\title{
EL POBLAMIENTO ROMANO EN LA CAMPIÑA SEVILLANA: EL TÉRMINO MUNICIPAL DE MARCHENA
}

\section{ROMAN SETTLEMENT IN THE SEVILLIAN COUNTRYSIDE: THE MUNICIPALITY OF MARCHENA}

\author{
por \\ ENRIQUE GARCÍA VARGAS* \\ MERCEDES ORIa SEgURA* \\ Manuel Camacho Moreno*
}

RESUMEN

El artículo muestra los resultados parciales, para la época romana, de la prospección arqueológica superficial en el término municipal de Marchena. Se localizan 114 yacimientos con material romano encuadrables en las categorías de aglomeración rural, uilla y pequeño asentamiento, de diferente vigencia a lo largo de tres amplias etapas: República-período augústeo, Alto Imperio y siglo III-Bajo Imperio. En un territorio repartido en la Antigüedad entre tres ciudades de importancia, el municipio de Carmo y las colonias de Urso y Astigi, se constata un denso poblamiento favorecido por las condiciones del terreno y los recursos hídricos, que aprovecha en gran parte la red de asentamientos indígenas y progresivamente se adapta al modelo romano de ocupación rural, siguiendo una evolución histórica semejante a la del resto de la Bética.

ABSTRACT This paper shows the partial results, for the Roman time, of the archaeological survey carried on the municipal term of Marchena. An amount of 114 sites with Roman items are located, belonging to the categories of village, uilla and small settlement, along three wide chronological stages: Republic-Augustean period, Early Empire and III ${ }^{\text {Td }}$ century-Late Antiquity. A dense occupation is verified in this territory, distributed among three important cities, the municipium of Carmo and the colonies of Urso and Astigi, favoured by the land conditions and the water resources. It largely takes advantage of the net of indigenous settlements and progressively adapts itself to the Roman pattern of rural occupation, following a historical evolution similar to the rest of Baetica.

Palabras claves Prospección arqueológica superficial. Marchena. Romanización. Territorio. Ocupación rural.

Key words

Archaeological survey. Marchena. Romanisation. Territory. Rural occupation.

* Universidad de Sevilla, Departamento de Prehistoria y Arqueología. Grupo de investigación "De la Turdetania a la Bética", proyecto La formación de la Bética romana (DGES, PB97-0736; II PAI, HUM-152). 


\section{I.- LA PROSPECCIÓN DEL TÉRMINO MUNICIPAL DE MARCHENA}

Presentamos aquí las conclusiones parciales, referidas a la época romana, de la prospección arqueológica superficial en el término municipal de Marchena (Sevilla) llevada a cabo en 1999 por el grupo de investigación "De la Turdetania a la Bética", en el marco del proyecto La formación de la Bética romana. El homenaje que la revista Spal ofrece al Prof. D. Manuel Pellicer con motivo de su jubilación nos parece especialmente adecuado para ello, si tenemos en cuenta que el Prof. Pellicer, durante sus años como director del Departamento de Prehistoria y Arqueología de la Universidad de Sevilla, impulsó la realización de las "Cartas Arqueológicas" de un buen número de municipios andaluces, encargadas como Tesis de Licenciatura bajo su dirección.

La prospección de términos municipales sigue una tradición bien asentada en la Arqueología española, la de las llamadas Cartas Arqueológicas. Éstas nacieron en los años 40 a escala provincial, integradas en la política de catalogación monumental del C.S.I.C. (Olmos 1993). Desde los años 80 esta política evoluciona de acuerdo con las nuevas concepciones internacionales sobre el Patrimonio Histórico, Arqueológico y cultural en general, siguiendo la tendencia de elaborar inventarios en los que la finalidad administrativa de catalogar y proteger los yacimientos arqueológicos se combina con objetivos de investigación (FernándezPosse - Álvaro 1993; en otros países como Italia, ya se desarrollaba esta tendencia desde los años 50: Potter 1982). Las transferencias en estas materias a los gobiernos autonómicos permiten precisar más el ámbito de actuación, resultando el término municipal una unidad de trabajo cómoda a efectos administrativos. Este motivo justifica que nuestra prospección haya revestido la forma tradicional de una Carta Arqueológica de término municipal, tramitada en este caso por el procedimiento de urgencia.

Como objetivos de carácter científico, desarrollamos un proyecto de investigación que obtiene de la prospección superficial gran parte de su documentación. Este proyecto no sigue exactamente la línea de la Arqueología del Paisaje, de planteamiento "ecológico"(Orejas 1998: 13-15; v. en general Cambi - Terrenato 1994), ni tampoco los últimos desarrollos globalizadores que plantean la posibilidad de obtener una visión sintética y en diacronía de las relaciones sociales a través del paisaje (Sastre 2001; Orejas 1991, 1998). Nuestro interés se reduce, en esta fase del trabajo, al aspecto político y económico del paisaje como ámbito "territorializado", esto es, repartido y gestionado por comunidades civiles diferentes, cuyas diversas estrategias sociales y distintos avatares históricos imponen características también peculiares a la forma que reviste en sus respectivos territoria el fenómeno llamado "romanización" (Sáez 1998). El ámbito políticoadministrativo que, dada la orientación actual de la política de actuaciones arqueológicas de la Junta de Andalucía, nos hemos visto obligados a adoptar nos impide, de momento, acercarnos al estudio de la región y su paisaje, como conceptualización histórica de más amplio alcance que la de territorio.

El término prospectado muestra dos sectores muy diferentes desde el punto de vista del paisaje y las posibilidades de aprovechamiento. Coinciden aproximadamente con las mitades N. y S., con una línea imaginaria de división a la altura del núcleo urbano de Marchena. En la mitad N., la más fértil, encontramos una sucesión de suaves colinas formando auténticas "cadenas" paralelas, las llamadas Loma Verdeja, Loma de la Lombriz, La Platosa, Cerros de San Ignacio, etc. y, algo más abruptos, los Cerros de Montalbán y Loma del Mostazar en la franja N. del término. El río Corbones, su afluente el arroyo Salado y otros arroyos que concentran en sus orillas la mayor parte de los yacimientos atraviesan el término con una tendencia general de S. a N., que se modifica río abajo para tomar la dirección E.-O. Excepto el Corbones y el Salado, se trata en su mayoría de arroyos estacionales secos casi todo el año, en una zona cuyo índice de pluviosidad es uno de los más bajos de la provincia, $461^{\prime} 7 \mathrm{~mm}$. anuales. Estas condiciones imponen cultivos extensivos de secano como olivar, cereales y girasol, mayoritarios en un término donde los suelos sedimentarios sobre calizas y margas son la nota dominante (Estudio agrobiológico...1962: Cap. 2.2). En la mitad S. el terreno es más arenoso y mucho más llano, lo que hace destacar sobre su entorno alturas moderadas como La Torre, 
la Atalaya Alta o Montemolín. La proliferación de topónimos como Palmar, Palmarete, Palmeños, etc. es indicativa de la vegetación natural y también se conservan amplias zonas dedicadas a dehesa ganadera y a eucaliptales, aunque los sectores cultivados repiten la pauta de la zona N. Esta mitad S. se encuentra además mucho más alterada por obras de urbanización en el entorno de Marchena y por la construcción de la autovía A-92.

A la hora de decidir la estrategia de prospección debíamos tener en cuenta estas condiciones, y también las habituales de los yacimientos que más directamente interesaban a nuestro proyecto, los orientalizantes, turdetanos y romanos. Para evitar los riesgos de una prospección "dirigida" o "intencional", limitada a cierto tipo de información, ésta se planteó como un muestreo estratificado con dos grandes estratos o zonas de diferentes características, precisamente las mitades N. y S. del término (v. sobre esta técnica Ruiz-Zapatero Fernández 1993: 91-92). En la parte N., más adecuada a priori para el tipo de asentamiento que buscábamos, se seleccionó la mayor parte de los cuadros de $1 \mathrm{~km}^{2}$ de la malla 1:50.000 en el Mapa Topográfico Nacional, con lo que el resultado se aproxima a la prospección de cobertura total. En la parte S., en teoría menos fructífera, se seleccionaron aleatoriamente los cuadros a prospectar. El trabajo se completó con la revisión de los enclaves ya conocidos y con una selección probabilística de lugares apropiados para el asentamiento, que obtuvo unos resultados irregulares. La extensión prospectada ha sido de $222 \mathrm{~km}^{2}$, el $58 \%$ de un término que comprende en total $378 \mathrm{~km}^{2}$, con el resultado de 209 yacimientos localizados, 114 de los cuales presentan material romano y son analizados en el presente trabajo.

Desde el punto de vista histórico, el territorio elegido puede plantear algunos problemas que dado el objetivo del estudio tal vez no lo sean tanto. La cuestión más relevante resulta ser que el término actual de Marchena, tomado como unidad de análisis, no coincide, pese a la insistencia al respecto de algunas tradiciones locales, con ninguna entidad territorial antigua. En él confluyen los límites entre los territorios de Carmo, Astigi y Urso durante las épocas republicana y julio-claudia, como explicaremos más adelante. Tal vez ello constituya su principal interés, pues si somos capaces, aunque sea a grandes rasgos, de delimitar el espacio ocupado por cada una de estas unidades administrativas antiguas, se nos ofrecerá la posibilidad de comparar sus respectivos esquemas de territorialización en el marco global de la "urbanización del campo" que parece constituir la característica fundamental de una ordenación territorial "a la romana", al menos en las zonas de más temprana y efectiva "colonización".

El interés de la prospección como herramienta para el análisis histórico de la romanización (v. Barker Lloyd eds. 1991 y su recensión, Mattingly 1993) y sus precedentes protohistóricos es evidente, por la abundancia y calidad de la documentación y por ser prácticamente la única fuente de información disponible, para una zona apenas mencionada en los textos antiguos. El uso de esta evidencia está sometido a precauciones, como uno de los planteamientos más interesantes de la Arqueología del Paisaje nos advierte. Se trata del concepto de arqueología off-site (tomada de Foley 1981), que ha evolucionado progresivamente desde la contextualización de los materiales de superficie no coincidentes con yacimientos arqueológicos, al interés por el estudio individualizado de los hallazgos sin referencia inmediata a su relación o no con yacimientos (v. la metodología de trabajo aplicada en el ager Tarraconensis: Millett 1994: 176-178, o, en otro contexto, compárense dentro del mismo proyecto regional de Beocia la conceptualización de J. Bintliff (1985) y A. Snodgrass, (1990 [1987]), quienes ya se interesan por el material off site, y la de Gilling y S. Sbosnias 1999). Las limitaciones de la prospección residen sobre todo en el hecho de proporcionar únicamente hallazgos superficiales, alterados por las prácticas históricas de abonado y los procesos post-deposicionales, ya sean de tipo antrópico (cultivo, construcciones), ya sean de origen natural (erosión). Esto no puede pasarse por alto a la hora de proponer, por ejemplo, una clasificación basada en el área de dispersión de los restos de superficie (Ruiz del Árbol 2001) y puede dar lugar a equívocos en la catalogación cronológica o funcional de un determinado yacimiento. Para completar sin lugar a dudas la caracterización de los yacimientos, habría que tener en cuenta su evolución diacrónica o cuestiones más complejas relacionadas con la recepción 
histórica de las vajillas "datantes", o con la "visibilidad" de ciertos elementos arqueológicos en función del estado de la investigación. Muchas de ellas sólo pueden aclararse mediante métodos de trabajo diferentes al de la simple prospección de urgencia, que sin embargo arroja una documentación susceptible de interpretarse con ciertas garantías, a falta de que microprospecciones y excavaciones en determinados yacimientos confirmen al $100 \%$ esta primera fase de trabajo, que no otra cosa es la prospección superficial.

Es evidente que la Carta Arqueológica del término municipal de Marchena no puede considerarse un estudio definitivo, como no lo son los datos sobre la ocupación de esta zona de la campiña durante el período romano que se presentan aquí. El estudio histórico global de la zona deberá tener en cuenta además la documentación de las áreas vecinas, pero al menos la prospección es una herramienta útil a la hora de aportar un volumen importante de datos, que sirvan como base al trabajo posterior.

\section{II.- LOS YACIMIENTOS ROMANOS DE MARCHENA}

\section{II.1.- Criterios de ordenación}

La prospección ha permitido detectar un total de 114 yacimientos con material romano en superficie, de características diferentes y no todos simultáneos. Ya hemos hecho referencia a las precauciones con las que debe utilizarse la documentación obtenida de una prospección superficial. Más delicado es aún asignar cada yacimiento a un tipo concreto dentro de una escala jerárquica, procedimiento que constituyó, debe recordarse, el experimentum crucis de la llamada "Arqueología Espacial", por cuanto determinaba las posibilidades de inferir conclusiones significativas del análisis espacial (Hodder y Orton 1990 [1976]).

En lo que se refiere a la arqueología romana, lo habitual es identificar concentraciones más o menos extensas que incluyan vajilla fina de mesa y materiales lujosos de varios tipos (restos de mosaicos, placas de mármol, restos de estucos) con la figura de la uilla rustica, mientras que el resto de los asentamientos se distribuye en una escala relativamente reducida de categorías que incluyen granjas rústicas, aglomeraciones rurales y necrópolis (Ponsich 1974, 1979, 1989, 1991, para el valle del Guadalquivir; Durán - Padilla 1990, para el cercano término de Écija). La tendencia a considerar la uilla rústica en sí misma, de acuerdo con un concepto "monumentalista" de la arqueología, y no en relación con el fundus que la acoge y al que organiza (D'Arbois de Jubainville 1886) nos ha hecho olvidar a menudo que la uilla es una realidad económica y jurídica más que un fenómeno arquitectónico (Carandini 1989).

Con todas las limitaciones inherentes al hecho de manejar únicamente material superficial, hemos tratado de contrastar la información disponible con lo que conocemos acerca de los modos de ocupación y explotación del medio rural durante el proceso de "romanización" y el posterior desarrollo provincial. En lo que a nuestra prospección se refiere, su carácter de urgencia y la imposibilidad técnica de proceder de momento a un adecuado análisis off-site condicionan la interpretación en el sentido de que sólo se consideran aquellos lugares cuya densidad de hallazgos permite, en las condiciones normales de un terreno de campiña habitualmente arado, identificarlos con alguna garantía como yacimientos romanos. Respecto a la funcionalidad de los mismos, hemos seguido los criterios comunes de extensión y carácter del material que si bien no tienen aplicación universal, pueden considerarse con carácter general adecuados para las zonas nucleares del valle del Guadalquivir, según los resultados obtenidos en zonas cercanas de características similares. Con una salvedad: hemos llamado uilla, de acuerdo con un criterio más jurídico-agrario (ciudadanía, propiedad privada) que monumental (partes suntuosas) (cfr. Pérez Losada 1987), a cualquier edificación rural de cierta entidad, independientemente del carácter lujoso o no del material de superficie, lo que entendemos evita las engorrosas distinciones entre establecimientos de primer o segundo orden (Cfr. Carrillo - Hidalgo 1991 para el cercano término de Palma del Río) cuyo trasfondo es más el de la edificación representativo-suntuosa que el de unidad de explotación agraria. 
A partir de la documentación de superficie hemos distinguido entre:

- Aglomeraciones rurales: yacimientos de extensión superior a 5 Has. en los que se localizan materiales constructivos, elementos de decoración arquitectónica y cerámica de todas clases en gran abundancia. También incluimos en esta categoría algunas agrupaciones de pequeños yacimientos muy próximos con aspecto de posibles aldeas.

- Villae: yacimientos entre 5 y 1 Has. con materiales constructivos y decorativos, cerámica de mesa, cocina y almacenamiento, molinos de mano, pesas de telar, etc.

- Granjas y pequeños asentamientos indeterminados: yacimientos menores de $1 \mathrm{Ha}$. donde predomina el material de construcción y la cerámica común, aunque pueden encontrarse también fragmentos de cerámica "fina".

- Otros: dependencias industriales, necrópolis, etc. cuya extensión puede ser variable y presentan estructuras y materiales característicos como hornos, restos de alfar, abundancia de tégulas, etc.

Estos criterios no pueden aplicarse sin más a todas las etapas y de hecho, corresponden fundamentalmente al período altoimperial. Una uilla, por referirnos al asentamiento más característico, no presenta la misma entidad en época republicana que en el Bajo Imperio. Las fundaciones romanas más antiguas parecen tener muy en cuenta las condiciones geográficas, ligadas a la existencia o no de establecimientos prerromanos, mientras sus dimensiones son modestas en la mayoría de los casos. Por el contrario, en el Bajo Imperio la mayoría de los asentamientos conservados corresponden a la categoría de uillae de grandes dimensiones. Por tanto, no en todos los períodos se seguirá rígidamente. Algunos de los yacimientos se reducen al hallazgo disperso de cerámicas comunes y tégulas en una gran extensión de terreno sin características definidas, caso de las Laderas de Montalbán y Las Motillas IV.

En cuanto a la adscripción cronológica de los mismos, se basa en el hallazgo de cerámicas características: campaniense, terra sigillata de fabricación itálica (TSI), sudgálica (TSG), hispánica (TSH) y africana (TSC), ánforas, etc., de tipología bien conocida y fechada, aunque la amplitud cronológica de algunos tipos, como las ánforas Dressel 20 o formas de sigillata en vigor entre los siglos I y III, permite poca precisión. Materiales característicos de la etapa republicana son la cerámica Campaniense A (Lamb. 3, Lamb. 27, Lamb. 28, Lamb. 31, Lamb 33 y 33b), en menor medida la Campaniense B (Lamb. 3, Pasquinucci 127) y C, así como ánforas Dressel 1 y grecoitálicas. Para el siglo I d.C. nos guiamos entre otras por la TSI, la cerámica de barniz rojo julio-claudio, la de paredes finas, la terra sigillata "precoz" y formas concretas de TSH y TSG como las Ritterling 8, Dragendorff 17, 18,29,33; así como las ánforas Haltern 70 y Dressel 2/4 y Dressel 7/11. Para mediados del siglo I, nuevas formas de TSG y TSH como las Dragendorff 24/25, 30, 37, 29/37, etc. fechables desde Claudio, la sigillata clara A (Lamboglia 1B, 4A, 5A, 18/31, etc.) y común, africana de cocina (Lamboglia 10, Ostia III 332 y 324) propias del período flavio en adelante son los indicadores cronológicos más precisos. Los datos más seguros a partir de principios del s. II provienen de la TSH (Dragendorff 29, 33, 35), la TSC A (tipos Lamboglia 1A, 2A, 3A, 3C, 5, Clara 6C, Hayes 3, 3c, 6c, 9a, 14a1) y la cerámica africana de cocina (tipos Ostia I 270, Ostia III 267, Lamboglia 10B), junto con ánforas como Beltrán IIB. No olvidemos que el material de ciertas épocas como el siglo III no está tan definido como el de otras, que el suministro de cerámicas de importación no es uniforme en todas las épocas y que por tanto, una disminución en la densidad de hallazgos no significa automáticamente una reducción de población (Millett 1994: 178).

A partir de esta periodización, encuadramos los yacimientos en tres amplias etapas históricas con unos límites cronológicos establecidos a grandes rasgos: República, siglos II-I a.C.; Alto Imperio, siglos I-II d.C.; y siglo III (una etapa de transición con características propias) - Bajo Imperio (siglos IV-VI). Dentro de ellas realizamos subdivisiones, ya que períodos concretos como los de César y Augusto, los Flavios o el siglo III traen cambios decisivos en la forma de ocupar el territorio rural. 


\section{II.2.- Período republicano}

La implantación romana en el territorio de Marchena se caracteriza por la presencia de numerosos asentamientos rurales de los cuales una pequeña parte, 6 en total $(5,2 \%)$ son de nueva fundación (Verdeja III-n ${ }^{\circ} 46$, Cortijo José Antonio-n ${ }^{\circ} 95$, La Gamorra-n ${ }^{\circ}$ 97, Los Isidros III- $n^{\circ} 108$, Lomas del Maravilloso II- $\mathrm{n}^{\circ} 128$ y Ojuelos- $\mathrm{n}^{\circ} 162$ ). El resto son asentamientos previamente existentes, que como tales seguirían funcionando con relativa normalidad hasta al menos la época cesáreo-augústea $(18,4 \%)$. La aparición en ellos de material itálico (barnices negros y ánforas vinarias) debemos encuadrarla en el ámbito de las importaciones de cerámicas y mercancías alimenticias. A partir del material cerámico recogido en superficie atribuimos a los siglos II y I a.C. un total de 27 yacimientos. Para el siglo II a.C. tenemos con seguridad 8 yacimientos que ofrecen una cronología precisa: Tarajal ( $\left.n^{\circ} 12\right)$, Santa Ana I ( $\left.n^{\circ} 17\right)$, Los Galindos II $\left(n^{\circ} 24\right)$, Porcún I ( $\left.n^{\circ} 68\right)$, Pozo del Carretero ( $\left.n^{\circ} 75\right)$, Cortijo José Antonio ( $\left.n^{\circ} 95\right)$, La Gamorra $\left(n^{\circ} 97\right)$ y Cortijo del Ahorcado ( $\left.n^{\circ} 119\right)$. Si consideramos aquellos que ofrecen cronologías largas el total se eleva a $17\left(\mathrm{n}^{\circ} 21,36,46,49,69,82,85,145,204\right)$. Para el s. I a.C. se documentan 7 yacimientos con material itálico en los que predominan las ánforas Dressel I B. Tan sólo 2 se crean en este momento: Verdeja III $\left(\mathrm{n}^{\circ} 46\right)$ y Los Isidros III $\left(\mathrm{n}^{\circ} 108\right)$ y el resto tienen claros precedentes turdetanos: Cerros de San Ignacio $\left(n^{\circ} 63\right)$, Porcún II ( $\left.n^{\circ} 69\right)$, La Zorrilla II ( $\left.{ }^{\circ} 83\right)$, La Torre ( $\left.n^{\circ} 85\right)$ y Los Palmeños ( $\left.n^{\circ} 204\right)$.

Dadas las características de la zona, donde predomina un relieve suave de llanos y lomas, excelentes para la agricultura, el panorama queda limitado de forma general a los asentamientos relacionados con la explotación de esos recursos y posiblemente de la ganadería. No parece indicado aplicar a este periodo la clasificación de los yacimientos en aglomeraciones rurales, uillae o granjas, ya que la concentración o dispersión de materiales de diferentes épocas en los mismos sólo permite documentar la extensión general, que puede variar de un período a otro. Por ello hemos preferido distinguir el tipo de asentamiento en función de la aparición en ellos de material de origen itálico y de la relación existente con su situación físico-territorial (el mismo criterio seguido en tierras castellonenses por Arasa 2001: 172 ss.). Teniendo en cuenta estas condiciones pueden distinguirse:

\section{A) Asentamientos en cerros}

Los asentamientos de este tipo corresponden siempre a núcleos de población turdetana, 14 en total: $n^{\circ} 63,67,68,69,75,82,83,85,102,142,145,153,179$ y FT 5 , de los que destaca Vico $\left(n^{\circ} 153\right)$ por su entidad como poblado ocupado desde el Bronce Final. Por el contrario, los de nueva creación no se sitúan en cerros. Tres se abandonan antes del Imperio, sin atisbo de continuidad posterior: Pozo del Carretero $\left(\mathrm{n}^{\circ} 75\right)$, Cagancha $\left(\mathrm{n}^{\circ} 179\right)$ y Donadío II (FT 5). La mayor concentración de yacimientos de tradición turdetana se encuentra a un lado y otro de la actual carretera Marchena-Carmona, en el vértice N.O. del término. La repercusión en éste área de la II Guerra Púnica, la pérdida gradual de categoría de enclaves de primer orden a partir de dicho hito histórico (zona de Porcún y San Ignacio) y la creación de nuevas uillae a comienzos del Imperio hace que muchos de éstos núcleos turdetanos se abandonen hacia la primera mitad del s. I d.C. $\left(n^{\circ} 63,82,83\right)$ y otros hacia la segunda mitad del s. I d.C. $\left(n^{\circ} 68,69,85\right)$. Tan sólo uno muestra evidencia de continuidad hasta el siglo II d.C.: Los Medianos III ( $\left.n^{\circ} 102\right)$, que alcanza la categoría de gran uilla en un pequeño cerro junto al arroyo Salado y el río Corbones. En la parte meridional se sitúan los $n^{\circ} 142,145$, 153 y 179 , que tampoco tienen una larga vida: el $n^{\circ} 142$ tal vez hasta la primera mitad del siglo II d.C., el $\mathrm{n}^{\circ} 145$ hasta siglo I d.C. como el $n^{\circ} 153$ (Vico) y el $n^{\circ} 179$ termina en el propio siglo I a.C. Su extensión media oscila entre $1 \mathrm{Ha}$. (Porcún Alto- $n^{\circ} 67$ ) y 5,7 Has. (Porcún I-nº 68), a poca distancia unos de otros. Su situación en altura, muy propia de los asentamientos indígenas y en especial de los de mayor entidad 
(en nuestro caso, Vico y zona de Porcún, futuras "aglomeraciones rurales" altoimperiales), les confiere una gran visibilidad, controlando áreas de fértil agricultura y tránsito de ganadería. Otros en cambio tienen una visibilidad algo más limitada en alguna dirección por algún cerrete vecino de similar altura (La Torre II, La Zorrilla, Pozo del Carretero) o por la cercanía de los de mayor envergadura (Porcún). En la zona meridional $\left(n^{\circ} 142,145\right)$ la visibilidad es buena en dirección al menos a dos puntos cardinales, pero limitada en alguna dirección a alrededor de $1 \mathrm{Km}$.

\section{B) Asentamientos en ladera y loma}

Otros asentamientos en cambio se sitúan en laderas o pequeñas lomas. Aquí reside la mayor novedad en cuanto a la dinámica poblacional, ya que la mayoría se crea con la llegada de la romanización en el área del Corbones y arroyo Salado, en la mitad N.E. Son 7 en total: Verdeja III ( $\left.\mathrm{n}^{\circ} 46\right)$, Cortijo de José Antonio ( $\left.n^{\circ} 95\right)$, La Gamorra ( $\left.n^{\circ} 97\right)$, Los Isidros III ( $\left.n^{\circ} 108\right)$, Cortijo del Ahorcado ( $\left.{ }^{\circ} 119\right)$, Lomas del Maravilloso II $\left(\mathrm{n}^{\circ} 128\right)$ y Ojuelos $\left(\mathrm{n}^{\circ} 162\right)$. Tan sólo dos tienen un origen turdetano: Rancho Los Galindos $\left(\mathrm{n}^{\circ} 24\right)$ y La Lombriz Ib $\left(n^{\circ} 49\right)$. Todos continúan en el Alto y Bajo Imperio, excepto dos que se abandonan al comienzo de época augustea $\left(\mathrm{n}^{\circ} 24\right.$ y 46$)$. Asistimos por tanto a la conformación de un eje claro de poblamiento en torno al arroyo Salado y el río Corbones, caracterizado por pequeños asentamientos dedicados a la explotación agrícola. Es una constante que se observa desde al menos época orientalizante, donde todo el área de SaladoCorbones es densamente colonizada con una red de pequeños establecimientos dedicados a la actividad agrícola. La parte meridional del término ofrece escaso poblamiento en ladera $\left(\mathrm{n}^{\circ} 162\right.$, cerca del Salado y La Coronela), aunque en cualquier caso ha sido menos intensamente prospectada. El disponer de cursos de agua cerca por tanto es un hecho fundamental. Predomina, decimos, el pequeño asentamiento rural que no sobrepasa incluso en época imperial $1 \mathrm{Ha}$., salvo dos yacimientos que se van a erigir como grandes uillae, La Gamorra ( ${ }^{\circ}$ 97) y La Lombriz Ib (n $\left.{ }^{\circ} 49\right)$, en torno a 5 Has. La escasez de material itálico que hallamos (Campaniense A en poca cantidad y B tipo Lamb. 3) tal vez indica que se trata de pequeños asentamientos rurales relacionado con el trabajo estacional en el campo, como se atestigua en otras zonas de la Campiña (Ruiz 1985: 249). La distancia media entre los grupos más cercanos es de 1.200 m ( $n^{\circ} 46-49,95-97,102-128$, 108-119).

\section{C) Asentamientos en llanura}

Por último hay un grupo más reducido, el de aquellos asentamientos que se sitúan en llanuras, 4 en total: Tarajal ( $\left.n^{\circ} 12\right)$, Santa Ana ( $\left.n^{\circ} 17\right)$, Los Felipes III $\left(n^{\circ} 21\right)$ y Clarebout $\left(n^{\circ} 36\right)$. Todos perpetúan núcleos indígenas pero tan sólo Tarajal y Los Felipes III funcionan hasta el Bajo Imperio como grandes uillae. Clarebout ( $\left.\mathrm{n}^{\circ} 36\right)$ acaba en el Alto Imperio y Santa Ana se abandona en la misma época republicana. Todos están muy cerca unos de otros, con una distancia media de $500 \mathrm{~m}$. y todos a orillas del arroyo Salado. Esta situación puede estar en relación con la obtención de pastos para el ganado u otras actividades agropecuarias. Su visibilidad media es infinita en dirección E.-O., limitada por suaves lomas hacia el S. y por el N. con la cadena de cerros del Mostazar y Montalbán. En todos encontramos Campanienses tipo A (una pieza) y ánforas vinarias Dressel 1.

Los hallazgos característicos de estos yacimientos en el período estudiado son, junto a las cerámicas turdetanas más tardías, los materiales importados de origen itálico, indicio de la entrada de la comarca en la órbita de la romanización a comienzos del s. II a.C. Este fenómeno está vinculado a la presencia de las tropas romanas a raíz de la II Guerra Púnica y las campañas llevadas a cabo para sofocar la rebelión 
del 197 a.C. Los hallazgos cerámicos que nos permiten establecer una cronología precisa son escasos, fenómeno que viene a ser frecuente en todo el valle del Betis, como ya apuntaba Gorges (1979: 26). Destaca la vajilla de mesa, Campaniense A (Lamb. 3, 27, 28, 31, 33 y 33b), en menor medida la Campaniense B (Lamb. 3, un fragmento de Pasquinucci 127) y la imitación en un caso de Campaniense C. Además se encuentran ánforas Dressel 1 (sobre todo B) y grecoitálicas, contenedores de ese producto tan característico del comercio de importación en este momento como es el vino. Vajilla fina de mesa y vino van a constituir poderosos elementos de integración cultural.

\section{II.3.- Período altoimperial}

Un total de 105 yacimientos presenta materiales fechables entre los ss. I-II d.C., de los cuales 51 estaban ocupados en las épocas precedentes y 91 se constatan ya en época julio-claudia. Es decir, que a comienzos del Imperio la ocupación rural en el término de Marchena casi se duplica y se pueden considerar establecidas las líneas generales del poblamiento en el período altoimperial. A lo largo del mismo se detectará una reducción progresiva que beneficia a los enclaves mayores en detrimento de los pequeños. Sólo unos cuantos asentamientos perduran a lo largo de todo el período, coincidiendo casi siempre con uillae de cierta importancia.

La población se dispersa de manera regular en todo el término, con especial concentración en las orillas del Salado, Lomas de la Lombriz y Verdeja y el sector N.O. a lo largo de la actual carretera MarchenaCarmona. Los enclaves se encuentran muy próximos unos a otros, de modo que los más aislados (Ranchos

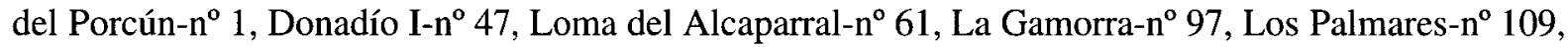
El Lavadero-n ${ }^{\circ} 137$, Haza de las Monjas- ${ }^{\circ}$ 200) tienen vecinos a distancias entre 1.500 y $2.500 \mathrm{~m}$. y lo más frecuente son las distancias entre 500 y 1.000 m., aún más reducidas en las orillas del Salado. Esta altísima densidad indica tal vez un cierto predominio de la pequeña propiedad que probablemente repercute en la forma de explotación agrícola. En varios casos están directamente asociados en grupos de yacimientos inmediatamente vecinos: Porcún Alto I-III + Porcún I-II, Santa Iglesia I-III, Los Felipes I-II, Los Galindos I-II, Los Medianos I y III, Vistalegre y Huerta Arjona. Por lo general consisten bien en varios asentamientos menores asociados, o bien en dependencias secundarias en torno a las uillae. Estas agrupaciones tienden a reducirse a lo largo del período, sobre todo por la citada desaparición de muchas de las "granjas" y dependencias de servicio. Donde más se acusa es en las orillas del Salado y en las Lomas de la Lombriz y Verdeja, donde aumentan las distancias entre vecinos a 1-2 km. como media. Llegada la segunda mitad del s. II d.C. sólo sobreviven 46 asentamientos, resultando especialmente llamativa la despoblación en zonas que anteriormente habían tenido una ocupación muy densa: arroyo Salado, Loma de la Lombriz, etc. También tienden a desaparecer las asociaciones de yacimientos, permaneciendo sólo los tres Santa Iglesia, Los Medianos I-II, Loma del Mostazar-Los Camorros, Repetidor I-II. En los demás casos sólo el núcleo principal sobrevive.

Los yacimientos se sitúan preferentemente en laderas y suaves lomas, aunque en los que ocupan cerro y ladera posiblemente sea el primero el asentamiento original y la pendiente la zona de dispersión y arrastre de materiales. Su visibilidad suele ser buena excepto en dirección a la cumbre del cerro correspondiente, con sólo 8 yacimientos prácticamente "encerrados" entre sus vecinos o en condiciones actuales poco favorables para la comprobación. En terreno llano con amplio radio de visión al menos en dos direcciones (excepto en cuatro casos de visibilidad muy limitada) hay 21 y en la cumbre de cerros de mediana altura, 18 generalmente con buena visibilidad aunque en alguno de los puntos cardinales esté limitada por otro cerro vecino; sólo 4 de los cerros se encuentran rodeados de alturas mayores que cierran drásticamente el campo de visión. La mayoría se sitúa a una distancia máxima de $500 \mathrm{~m}$. de un arroyo (Los Medianos I a $800 \mathrm{~m}$. del Corbones) o disponen de pozos en su interior y sólo 14 se encuentran lejos de puntos de agua. Estas características generales apenas cambian a lo largo del período, ya que los asentamientos de nueva creación a lo largo de los siglos I-II repiten el modelo sin variaciones. 


\section{A) Aglomeraciones rurales}

A principios de la época imperial nos encontramos con tres yacimientos o agrupaciones que podríamos calificar de "aglomeraciones rurales". Se trata de Vico $\left(n^{\circ} 153\right)$, cuyo nombre conservado hasta hoy hace pensar en la existencia de un auténtico uicus superpuesto a un poblado continuamente ocupado desde el Bronce Final; del Rancho Pozo Blanquillo $\left(n^{\circ} 86\right)$, con $90.000 \mathrm{~m} 2$ de superficie cubierta de restos constructivos y cerámicos; y del grupo de yacimientos en torno a Porcún - Porcún Alto (nº67-68-69), auténtica aglomeración de pequeños y medianos lugares de ocupación con material turdetano y romano, inmediatamente vecinos, cuya relación directa es más que probable. Los dos últimos se encuentran en el mismo sector, al N.O. del término en dirección a Carmona y separados por unos $7 \mathrm{~km}$., mientras el primero se sitúa mucho más al S., a orillas del Corbones. A mediados del siglo I d.C. se les añade un nuevo enclave junto al Corbones, casi en el límite N. del término. Lo denominamos Grullo Grande II - El Grullo ( $\left.n^{\circ} 7\right)$ debido a que en una prospección anterior se identificó como dos yacimientos separados, siendo en realidad partes de un único conjunto que supera las 7 Has. Esta aglomeración prolonga su vida hasta el siglo IV, mientras la documentación arqueológica sobre Vico se hace cada vez más imprecisa por la destrucción de las capas superiores del cerro.

A partir del siglo II es cuando se producen mayores cambios en este grupo. El más llamativo es la práctica desaparición de Porcún-Porcún Alto como aglomeración rural, reducida a un sólo punto con materiales de esa fecha en adelante. Por el contrario el crecimiento de Grullo Grande II-El Grullo es muy acusado. Junto con el Rancho Pozo Blanquillo, se convierten en los dos núcleos principales de población, ante la escasez de noticias seguras sobre Vico. Los dos serán los únicos que se mantengan con seguridad en la etapa bajoimperial.

En la actualidad estos yacimientos se presentan como extensos despoblados cubiertos de restos, sobre todo materiales de construcción entre los que abundan los ladrillos de diversas medidas, incluidos los laterculi de pavimentación y los de corte circular para fustes; tégulas e ímbrices y algunos elementos de piedra, tambores de columna (Grullo Grande) y bloques prismáticos. En Grullo Grande se observan aún sectores de pavimento en opus spicatum. Vico conserva una construcción de opus caementicium, similar a la base de un edificio cuadrangular, que Collantes (en Ordóñez 1996: 51; v. Oria 2001) identificó en su momento con un depósito de agua y que puede relacionarse con el acueducto subterráneo junto al Corbones en la ladera del vecino Montemolín (Ordóñez 1996: 52 según noticias de Collantes; Oria 2001), cuya zona principal, en la misma cumbre del cerro, deja de ocuparse tras la II Guerra Púnica.

En cuanto a los materiales, los molinos de piedra encontrados en este yacimiento y Porcún I son muy representativos de la actividad agrícola desarrollada en ellos. Abundan todas las clases cerámicas características de un núcleo de población, desde la vajilla de mesa (terra sigillata itálica, hispánica, sudgálica, africana A, paredes finas) hasta la común de cocina y almacenamiento, destacando tipos anfóricos como la Haltern 70 de Porcún II o las "omnipresentes" Dressel 20 y Beltrán IIb y los enormes dolia destinados a contener líquidos y cereales.

\section{B) Villae}

Constituyen el grupo más destacado de yacimientos altoimperiales, por su número y continuidad. De hecho y contando con la desaparición / nueva creación de varias de ellas a lo largo de los dos siglos, su número se mantiene constante en torno a la treintena, con una ligera disminución desde mediados del siglo II d.C. La segunda mitad del siglo I d.C. puede considerarse un momento de crecimiento, con la fundación de asentamientos tan destacados como Los Camorros I $\left(n^{\circ} 33\right)$ y el auge de El Toril $\left(n^{\circ} 173\right)$ y El Cañuelo I $\left(n^{\circ} 180\right)$. Por el contrario, en esa etapa desaparecen otras como el Cortijo de la Torre II ( $\left.{ }^{\circ} 159\right)$, lo que 
hace imposible la pretendida ubicación en el yacimiento de un municipio flavio, Artigi (v. infra). Todas las que se mantienen a partir del siglo II son uillae de cierta entidad y que ya funcionaban en las etapas anteriores, aunque el volumen de hallazgos con fecha segura tiende a reducirse. A lo largo de todo el Alto Imperio, las encontramos dispersas regularmente en todas las zonas del término, separadas por distancias entre 2,5 y $7 \mathrm{~km}$., aunque las distancias más habituales oscilan entre 4 y $6 \mathrm{~km}$. Aunque son frecuentes en las orillas del Corbones y el Salado, también se sitúan cerca de arroyos menores y lejos de fuentes de agua.

Apenas conservan estructuras emergentes, pero las que hay resultan muy significativas: además de un núcleo informe de opus caementicium de gran tamaño en Puntal de la $\mathrm{Jarda}\left(\mathrm{n}^{\circ} 122\right)$, las uillae de El Lavadero $\left(\mathrm{n}^{\circ} 137\right)$, Cortijo del Río $\left(\mathrm{n}^{\circ} 168\right)$ y El Toril $\left(\mathrm{n}^{\circ} 173\right)$ conservan obras de infraestructura hidráulica: depósitos a cielo abierto de opus caementicium revestido de opus signinum, de forma circular (El Toril) o rectangular (El Lavadero, Cortijo del Río), acompañados en El Lavadero por restos de un acueducto subterráneo y una gran cisterna cubierta (Oria 2001). Junto a los esperables restos de construcción, no son raros los restos de elementos decorativos: trozos de mármol de distintos colores (Los Felipes I-n ${ }^{\circ} 19$, Santa Iglesia III-n ${ }^{\circ} 79$, Repetidor II- $n^{\circ} 105$, Los Palmares-n $n^{\circ} 109$, Puntal de la Jarda- ${ }^{\circ} 122$, El Lavadero- $n^{\circ} 137$ ), fragmentos de estuco pintado (El Toril- $n^{\circ} 173$ ), una estatuilla muy mutilada de mármol (Los Mellizos- $n^{\circ} 130$ ), e incluso noticias respecto a mosaicos extraídos hace años en El Lavadero (Ordóñez 1996: 49-50), aunque la cronología de éstos puede ser posterior. Todo ello indica un cierto nivel de refinamiento en la construcción y el modo de vida de sus habitantes. No puede considerarse en cambio un objeto suntuario la figurilla femenina desnuda de terracota encontrada en El Grullo Grande $I\left(n^{\circ} 6\right)$, un tipo de amuleto muy habitual en toda clase de ambientes. Lo mismo ocurre con los restos cerámicos, abundantes y variados tal como ocurre en las aglomeraciones mayores, con tipos característicos que jalonan las etapas de su funcionamiento.

\section{C) Granjas y asentamientos menores}

Se trata del grupo más irregular y con mayores variaciones en cuanto a número, siempre descendente, densidad y ubicación. En la época julio-claudia son más de 30 y se encuentran dispersos regularmente por todo el término, con cierta preferencia por las orillas del Salado y las lomas de la Lombriz y Verdeja, donde se sitúan muy próximos unos a otros. Ninguno de ellos presenta restos emergentes de construcción ni elementos suntuarios. Sin embargo, los fragmentos de vajilla de mesa cuidada son por lo general tan frecuentes en estos pequeños asentamientos como en los mayores. Un buen número de ellos está asociado a yacimientos de mayores dimensiones, lo que probablemente indica una dependencia. Esta impresión se refuerza cuando los hallazgos son básicamente de cerámica común y material de construcción, aunque esta situación se da en muy pocos yacimientos (Loma del Mostazar II-no 32 ).

Desde principios del siglo II su número disminuye considerablemente. Los establecimientos que sobreviven a la contracción son tanto dependencias asociadas a uillae (Los Felipes II- $n^{\circ} 20$ con Los Felipes I, Loma del Mostazar II-n ${ }^{\circ} 32$ con Los Camorros I, Verdeja III-nº 46 con Verdeja IV, Santa Iglesia I y III-n 77 y 79 con Santa Iglesia II) como granjas "independientes" en el Salado, las Lomas de la Lombriz y Verdeja y la campiña entre el Corbones y la carretera hacia Carmona, estas últimas en número mayor. A mediados de este siglo se han reducido a 13 enclaves de continuidad dudosa, ya que los hallazgos se limitan a cerámica de cronología amplia dentro del siglo II. 


\section{D) Otros}

Un pequeño grupo de yacimientos presenta características bien definidas y diferentes a las citadas. En primer lugar, Vistalegre II $\left(\mathrm{n}^{\circ} 187\right)$ y El Toril II $\left(\mathrm{n}^{\circ} 174\right)$ son las necrópolis de las uillae correspondientes de Vistalegre y El Toril, la primera de ellas conocida sólo por bibliografía (Collantes, en Ordóñez 1996: 54) y la segunda asegurada por noticias orales sobre restos humanos, que concuerdan bien con el material encontrado: tégulas y cerámica común mayoritariamente. Aunque las dos muestran cerámicas fechables entre los siglos I-II d.C., el abandono de Vistalegre I a finales del s. I y la continuidad de El Toril I deben ser indicativos de la duración de ambas necrópolis.

Muy diferente en todos los sentidos es el horno para la fabricación de cerámica común encontrado junto al Corbones, Cortijo del Río I ( $\left.\mathbf{n}^{\circ} 167\right)$, sin duda dependiente de la vecina uilla Cortijo del Río II. Como los desechos de alfar en Los Camorros, testimonia una áctividad productiva en las uillae del término que va más allá del cultivo. El horno fue objeto de una excavación de urgencia en los años 80 , detectándose materiales de cronología amplia entre finales del siglo I y principios del siglo III (Romero 1987).

\section{II.4.- Siglo III y Período Bajoimperial - Tardoantiguo}

Sólo 40 yacimientos pueden atribuirse a los siglos III y IV d.C. en función de la cronología del material cerámico recogido en superficie. De ellos, 23 pueden asignarse sin apenas dudas al siglo III d.C., mientras el resto tiene una cronología indefinida entre los siglos II-IV d.C. La aparente desaparición de 14 yacimientos supone una reducción importante $(-42,2 \%)$. Con todo, debe tenerse en cuenta que bastantes (no podemos precisar con seguridad cuántos) de los que no presentan materiales diagnosticables debieron continuar su vida a lo largo del siglo III. Así podría ocurrir con tres cuya fundación se remonta a la primera mitad del siglo I d.C. y que presentan evidencias de estar en funcionamiento aún en el siglo IV: Rancho Pozo Blanquillo $\left(n^{\circ} 86\right)$, cuya existencia a partir de 150 d.C. es dudosa; La Gamorra $\left(n^{\circ} 97\right)$, con dudas respecto a todo el siglo II, y El Cañuelo I ( $\left.\mathrm{n}^{\circ} 180\right)$, sin materiales claros entre principios del III y el IV d.C. Si añadimos aquellos que presentan materiales con cronologías largas que pueden alcanzar el siglo III d.C. (yacimientos $\mathrm{n}^{\circ} 11,40,41,47,86,125,162$ y 168 ) el descenso con respecto al siglo anterior sería considerablemente menor: $-24 \%$.

Restringiendo el análisis a los establecimientos que con alguna seguridad pueden considerarse en funcionamiento a lo largo del siglo III d.C., puede observarse que 20 de ellos se encuentran situados en la mitad N. del término, quedando sólo 6 al S. de la localidad de Marchena, zona menos intensamente prospectada en cualquier caso. De los septentrionales, la mayoría, 12, se sitúa en la margen derecha del Corbones y 8 lo hacen en su margen izquierda. Los yacimientos del cuadrante nororiental (entre el Corbones, el límite municipal y la autovía Sevilla-Málaga) se sitúan sobre llanuras o laderas, raramente en cerros $\left(n^{\circ} 6\right)$, cercanos al arroyo Salado $\left(n^{\circ} 19,30,41,105,108,114\right.$, a menos $200 \mathrm{~m}$ de su curso actual) o al río Corbones $\left(n^{\circ} 12\right.$ y 25 a 650 y $400 \mathrm{~m}$ respectivamente). En esta zona parecen detectarse con claridad dos líneas de distribución del poblamiento rural: la ya señalada del arroyo Salado y la correspondiente a las lomas al N.E. del mismo, a uno y otro lado de la carretera de Écija $\left(\mathrm{n}^{\circ} 33,48,190\right.$ a su izquierda, 122 a la derecha). Por su parte, los $n^{\circ} 195$ y 108 se ubican en la confluencia del arroyo y la carretera.

En el cuadrante N.O. son uillae Ranchos del Porcún $\left(n^{\circ} 1\right)$, Grullo Grande I $\left(n^{\circ} 6\right)$, Santa Iglesia III $\left(n^{\circ} 79\right)$, Rancho Pozo Blanquillo ( $\left.n^{\circ} 86\right)$, Barragua II $\left(n^{\circ} 89\right)$, Cerro del Birrete $\left(n^{\circ} 96\right)$ y La Gamorra $\left(n^{\circ} 97\right)$, mientras que Cortijo de los Olivos I ( $\mathrm{n}^{\circ}$ 92) no parece pasar de una pequeña granja o establecimiento de menores dimensiones. Existe una mayor tendencia en esta zona a ocupar los cerros como en los casos de los yacimientos $n^{\circ} 6,86,89,96$ y 97 , encontrándose menos vinculados a corrientes de agua y, por lo tanto, dependientes 
de manantiales $\left(\mathrm{n}^{\circ} 79\right.$ y 86). La distribución espacial en este cuadrante parece regular a lo largo de la vega que delimitan la carrera de Carmona al O. y el Corbones al E. En la parte S. del término, el mayor grado de alteración de los yacimientos y la menor intensidad de la prospección tan sólo han permitido documentar 5 yacimientos con ocupación segura a lo largo del III d.C. Prácticamente todos se ubican en laderas suaves. De ellos, dos se vinculan al Corbones en su tramo más meridional ( ${ }^{\circ} 174-\mathrm{El}$ Toril II; $\mathrm{n}^{\circ}$ 180-El Cañuelo I), uno al Salado ( $n^{\circ} 163$-Pagodulce I), mientras que El Lavadero $\left(n^{\circ} 137\right)$ se sitúa junto a un manantial -arroyo y algunos de ellos (El Toril, El Lavadero) presentan estructuras hidráulicas de gran envergadura. De todos los yacimientos meridionales, que son siempre uillae, sólo Pagodulce I $\left(\mathrm{n}^{\circ} 163\right)$ se sitúa en la margen derecha del Corbones. Todo ello viene a indicar que el abastecimiento abundante de agua es una preocupación importante para sus propietarios.

El siglo V supone una drástica reducción del número de emplazamientos rurales en la campiña de Marchena. Eso al menos es lo que sugiere la ausencia de cerámica característica de estas fechas en el término, con la excepción de Santa Iglesia ( $\left.n^{\circ} 79\right)$, Barragua II $\left(n^{\circ} 89\right)$, Cortijo de los Olivos ( $\left.n^{\circ} 92\right)$, Cerro del Birrete $\left(n^{\circ} 96\right)$ Repetidor II $\left(n^{\circ} 105\right)$, Puntal de la Jarda, $\left(n^{\circ} 122\right)$, Transformador II $\left(n^{\circ}\right.$ FT 2$)$ y Rancho Fernandita $\left(n^{\circ}\right.$ FT 4). De un total de 40 yacimientos para los siglos III y IV se pasa a 8 , lo que supone un descenso del $80 \%$ del número total de emplazamientos agrícolas. El eje del poblamiento se traslada a la vega de Carmona, donde se sitúa la mitad de los yacimientos, aunque uillae con restos de construcciones y materiales suntuarios como Puntal de la Jarda y Repetidor II están situadas respectivamente junto al Salado y en las proximidades de la vía que transita en dirección a Astigi.

\section{A) Aglomeraciones rurales}

Sólo dos de los yacimientos así calificados para la etapa altoimperial, Grullo Grande II ( $\left.\mathrm{n}^{\circ} 7\right)$ y Rancho Pozo Blanquillo $\left(\mathrm{n}^{\circ} 86\right)$, parecen sobrevivir al siglo III y lo hacen de manera residual, atendiendo al volumen respectivo de restos cerámicos detectados y su poca precisión cronológica. La tendencia a la reducción de importancia es evidente en el caso de Grullo Grande II - El Grullo ( $\left.{ }^{\circ} 7\right)$, que debía ser un auténtico uicus altoimperial y cuya menor entidad en época tardía puede ser una falsa impresión, consecuencia de la retracción de las importaciones de cerámica fina de mesa con respecto al periodo altoimperial, un fenómeno que se ha señalado para otros territorios cercanos (Durán - Padilla 1990), y algo más alejados (Carreté et al. 1995: 280). En todo caso, el modelo de organización social al que se ligan estos yacimientos ha desaparecido ya en esta época.

\section{B) Villae}

Casi todos los establecimientos de este período pueden considerarse uillae por la extensión, por los materiales o por ambas cosas. La mayoría de las grandes uillae altoimperiales continúan su vida a lo largo del siglo III d.C. ( $\mathrm{n}^{\mathrm{o}} 1,6,12,19,25$ ?, 30?, 33, 48, 79, 89, 92, 96, 105, 108, 122, FT4). El Lavadero (n $\left.{ }^{\circ} 137\right)$ tiene su máxima expansión en esta época, de hecho pensamos que pueda ser el origen remoto de la población de Marchena por su extensión, riqueza de restos y cercanía al núcleo urbano (Ferrer et al. 2000: 101). También El Cañuelo ( $\left.n^{\circ} 180\right)$ es importante en el siglo III, lo mismo que sucede con Verdeja IV ( $\left.n^{\circ} 190\right)$.

Puede admitirse, pues, una cierta contracción del número total de explotaciones agrícolas como consecuencia no tanto de la crisis, como tal vez de la dinámica de concentración de las formas de propiedad y gestión que alcanza en la zona proporciones importantes a partir de los últimos Antoninos (Jacques 1990). La consecuencia fundamental es la reducción del número de establecimientos en zonas antes densamente 
ocupadas, como la cuenca del Salado (Los Felipes I-nº 19, La Charca II-nº 30; Repetidor II-n' 105 ) y las elevaciones de la Loma Verdeja, donde sólo sobreviven explotaciones de importante entidad como Verdeja IV $\left(n^{\circ} 190\right)$, Cerro Motilla ( $\left.n^{\circ} 48\right)$ y Los Camorros I ( $\left.n^{\circ} 33\right)$.

Con respecto al siglo IV, puede señalarse una cierta continuidad del poblamiento en el territorio objeto de nuestro interés, en el que todos los establecimientos de la centuria anterior continúan en activo. La única excepción clara parece ser la de Cortijo del Río II $\left(\mathrm{n}^{\circ} 168\right)$, uilla relacionada con las instalaciones alfareras excavadas en el Cortijo del Río I ( $\left.n^{\circ} 167\right)$ cuya desaparición debe coincidir con la de la uilla. Con los datos a nuestra disposición, no puede hablarse siquiera de revitalización agrícola, pues la creación de dos pequeños asentamientos que citaremos a continuación no parecen justificarla. Es verdad que un cierto número de uillae, Rancho Pozo Blanquillo ( ${ }^{\circ} 86$, que en el Alto Imperio alcanzaba las dimensiones de una auténtica aglomeración), La Gamorra ( $\left.n^{\circ} 97\right)$ y El Cañuelo I ( $\left.{ }^{\circ} 180\right)$, parece haber sufrido un hiatus poblacional a lo largo del siglo III, resurgiendo con fuerza en la cuarta centuria, pero no hay manera de saber si se trata de una realidad o de una falsa impresión fortuita provocada por no haberse recogido materiales claramente datados en el siglo III d.C. La larga perduración de estos tres yacimientos desde el siglo I d.C. hasta el IV al menos tal vez abogue por una ocupación ininterrumpida que incluya también el siglo III d.C. De los pocos yacimientos que continúan su vida en el siglo V d.C., Santa Iglesia III, Barragua II y Cerro del Birrete parecen ser uillae a juzgar por el material y / o las dimensiones y Cortijo de los Olivos un establecimiento menor. Repetidor II y Puntal de la Jarda son a su vez uillae de grandes dimensiones con material suntuario y restos de construcciones, sin embargo, de fecha imprecisa y ya activas en el Alto Imperio.

\section{C) Granjas y asentamientos menores}

Un fenómeno llamativo, que continúa una tendencia observada en la centuria anterior (supra), resulta ser la desaparición de un cierto número de granjas rurales dependientes de uillae en actividad a lo largo del III d.C. (Santa Iglesia III-n ${ }^{\circ} 79$; Barragua I- ${ }^{\circ} 88$, Repetidor I-n ${ }^{\circ}$ 104). Para el siglo III, tan sólo los establecimientos Salado IIb $\left(n^{\circ} 41\right)$, Los Isidros III $\left(n^{\circ} 108\right)$ y Carrascal IV $\left(n^{\circ} 114\right)$ corresponderían a granjas rústicas, de las que Los Isidros III parece depender de la villa de Repetidor II ( $\left.\mathrm{n}^{\circ} 105\right)$ mientras que Salado IIb tal vez dependa de Salado III y Carrascal IV de Los Isidros I. Se mantienen en funcionamiento sin embargo las situadas en la cuenca del Salado (Salado IIb- ${ }^{\circ} 41$ y Carrascal IV- $n^{\circ} 114$ ), un área tradicionalmente ocupada por establecimientos menores de los que, no obstante, Repetidor I ( $\left.\mathrm{n}^{\circ} 104\right)$, una de las dos "granjas" existentes en las proximidades de la uilla de Repetidor II ( $\left.\mathrm{n}^{\circ} 105\right)$, no parece superar el siglo II d.C.

Ya en el período bajoimperial se documenta la aparición de al menos dos nuevos enclaves: Pasada del Martillo I $\left(\mathrm{n}^{\circ} 10\right)$ y El Alcaparral II $\left(\mathrm{n}^{\circ} 62\right)$. En el primer caso, se trata de un pequeño establecimiento rural situado cerca de un vado del Corbones, con respecto al segundo, se trata un pequeño establecimiento sobre una loma en las leves estribaciones situadas en el extremo N.E. del término.

\section{III- LA EVOLUCIÓN DEL POBLAMIENTO}

\section{III.1. Colonización y municipalización: problemas de límites y de adscripción territorial}

La enorme vitalidad del poblamiento rural romano en el actual término municipal de Marchena, desde prácticamente inicios del Imperio y desde luego en época julio-claudia, parece indicar a las claras que nos encontramos ante un ámbito territorial de antigua y profunda romanización. Descartada la identificación de la actual población de Marchena con una hipotética Colonia Marcia, cuya existencia fue propuesta sobre 
la base de una inscripción falsa recogida por Rodrigo Caro (1634/1998: Cap. LI), parece imponerse la idea de que la actual jurisdicción municipal perteneció, por lo menos antes del proceso de municipalización impulsado en Hispania por la dinastía flavia, a las demarcaciones territoriales de las cercanas ciudades de Urso, Astigi y Carmo, respectivamente colonias cesariana y augustea y municipio augústeo. En estas ciudades con estatuto jurídico privilegiado es donde más temprano se consolidaron las formas de propiedad y de ordenación territorial propiamente romanas (Ferrer et al. 2000: 93).

La confluencia entre los límites de los respectivos territoria de estas ciuitates béticas debe encontrarse en la zona oriental del actual término de Marchena, si es que puede extrapolarse a la Antigüedad la situación reflejada en los repartimientos efectuados tras la conquista cristiana del territorio en los años centrales del siglo XIII d.C. (Sáez et al. e.p.). Inmediatamente después de ésta se constituye el término de Marchena, ocupando un amplio espacio territorial entre los alfoces de Carmona, Écija y Osuna. Al O. del término, el lugar llamado Cabeça de Corona y también Matacorona en las ordenanzas de los Guardas de Campo del siglo XVI, citado en el Repartimiento de Écija (texto en Hernández 1951; Sanz 1979; González 1989) como mojón de delimitación entre los territórios de Marchena, Écija y Osuna hasta la segregación de Osuna de La Lantejuela, pudo haber constituido desde antiguo un hito entre las jurisdicciones de Osuna y Écija.

El límite histórico entre los territorios de ambos municipios discurría desde la conquista por la línea que une Matacorona con Gallape, coincidiendo con la llamada Vereda Real del Mariscal. Ésta debió ser también linde entre los respectivos términos andalusíes, puesto que la delimitación territorial previa a las labores de repartimiento de cada municipio se hizo con "moros viejos y sabidores", tratando de reconstruir los viejos límites entre jurisdicciones islámicas. Si las demarcaciones anteriores a la conquista cristiana pueden considerarse de alguna manera herederas de los territoria romanos y visigodos, lo que desde luego no es más que una suposición ( $c f r$. Valencia 1988: 318 ss. e Id. 1998: 26), cabe proponer que esta misma Vereda Real constituyera la linde entre las tierras correspondientes a Urso y Astigi.

Al N.O. de Matacorona, la línea de elevaciones que se conoce como Loma Verdeja parece, de nuevo según las informaciones del Repartimiento de Écija, constituir la separación entre los territorios de Carmo y Astigi, toda vez que la segregación del término municipal de Fuentes de Andalucía es más reciente (siglo XVI). Dicho límite pudo estar marcado durante la Antigüedad, al igual que lo estuvo en la Edad Media, por el arroyo Madre de Fuentes cuyo nombre medieval es el de Guadalbardiella, compuesto con toda probabilidad por el genérico wadi (río) y el topónimo Bardiella > Verdiella > Verdeja. A grandes rasgos, pues, puede proponerse que los territorios de Carmo y de Astigi se hallaban delimitados en la zona que nos interesa por la cuenca del Guadalbardiella y, al S. del nacimiento de este río, por la divisoria de aguas que suponen las elevaciones de la Loma Verdeja, límite histórico entre Marchena y Écija antes del avance hacia el E. de la demarcación entre ambos territorios ya en el siglo XVI. Entre las estribaciones meridionales de la Loma Verdeja, la Vereda Real del Mariscal y la cuenca del Salado debe ubicarse el límite entre Astigi y Urso, sin que sea posible proponer un trazado claro para el mismo ni siquiera a título de hipótesis.

Todo lo anterior deja en la esfera jurisdiccional del municipio carmonense casi todo el actual término de Marchena, con una zona correspondiente a Astigi en el ángulo N.E. del mismo y otra algo más indefinida al S.E. correspondiente al territorio de Urso. Estos límites territoriales pudieron verse de algún modo alterados por la constitución a partir de fines del siglo I d. C. de municipios flavios como el de Obulcula (La Monclova), cuyo territorio segregado del de Astigi pudo incluir la zona de Fuentes de Andalucía y, circunstancialmente, el extremo N.E. del término de Marchena. Podría proponerse que en la propia Marchena se ubicase también algún municipio flavio de nombre desconocido como los que vamos conociendo un poco por doquier en esta zona de la campiña (González 1999; Stylow 1999), tanto si contaba con oppidum como si constituía una ciuitas sine oppido, por ejemplo en torno a algún manantial sagrado, como una inscripción dedicada a Salus procedente de Marchena (CIL II 1391) puede hacer pensar (Ordóñez 1996: 38). No puede sostenerse, por el contrario, la identificación del Cortijo de la Torre (nuestro yacimiento ${ }^{\circ} 159$ ) con la Artigi Iulienses 
de Plinio $(N H, 3,10)$ y Ptolomeo $(2,4,9)$ sobre la base de la inscripción fragmentaria CILA II.3, $816=$ AE, 1984: 512, que menciona a un tal Fabius cuyo origo ha sido reconstruido como [Arti]ciensis (González 1996: 192-193). Mal puede ser municipio flavio un yacimiento que no supera las dimensiones de una uilla rústica y cuyo material más reciente no es posterior a la época de Claudio.

La inclusión, al menos hasta época flavia, de parte del territorio de Marchena en el de Astigi puede, por otra parte, venir confirmada por la existencia en la Iglesia Mayor de Marchena de los epígrafes funerarios CIL II 1396 y 1398 (= CILA II.3 824-825), correspondientes a cuatro individuos de la Papiria, tribu a la que fueron asignados los colonos astigitanos tras la fundación de la Colonia Augusta Firma Astigi por Augusto en torno a 14 a.C. (Ordóñez 1988).

En la zona E., que debió formar parte de los territorios de Astigi y Urso, era factible encontrar trazas de centuriación, de la que sin embargo no hemos localizado huella ninguna. Esto no es de extrañar, por cuanto la pértica centuriada no ocupa la totalidad del territorio colonial, sino sólo aquella que será objeto de reparto. En el caso de Écija (Sáez et alii e. p.) ésta ha sido localizada en el extremo sudoriental del actual Término ecijano, una zona tradicionalmente vinculada con los cultivos de secano: 53, 62 .

En cuanto a la amplia zona perteneciente a Carmo, el estatuto de esta comunidad permitiría conservar la forma de propiedad y explotación prerromana. De hecho, 51 de los 105 yacimientos altoimperiales tienen precedente turdetano, aunque su importancia relativa puede variar de una etapa a otra, y la mayoría se encuentran precisamente en la parte occidental. Los yacimientos que por su extensión y abundancia de restos hemos considerado aglomeraciones rurales son continuación de importantes poblados turdetanos con material republicano, lo que casa bien con la pervivencia de la organización social prerromana documentada también por la epigrafía (Chic 1993; Sáez 1978 y 1999)

\section{III.2.- El período republicano}

El análisis e interpretación del poblamiento romano-republicano de esta zona debería partir en gran medida del análisis de fases anteriores, en virtud de un hecho fundamental como es la continuidad que se detecta en numerosos asentamientos. No es demasiada la información con la que contamos, pero a partir del trabajo de prospección realizado y con todas las limitaciones que se derivan de la información proporcionada vamos a intentar establecer unas pautas generales de ocupación del territorio en la época romana republicana.

Detectar el poblamiento de época republicana en el término estudiado plantea algunos problemas. Si sólo se consideran como tales los yacimientos que tienen materiales importados de fecha republicana, como cerámica campaniense y algunos tipos de ánforas, se reducen a 26. Se pueden interpretar en dos sentidos:

a) considerarlos asentamientos romanos de nueva planta, ocupados por inmigrantes recién llegados

b) continuidad de los turdetanos, quizás con algunos habitantes nuevos y sobre todo con nuevas producciones que empiezan a llegar por los cauces comerciales normales: vajilla de mesa campaniense y ánforas de fabricación itálica.

La segunda alternativa parece más aceptable porque la mayoría de los yacimientos no son de nueva creación. De todas formas son muy pocos, en comparación con los períodos anterior y posterior. Incluso considerando que tras la II Guerra Púnica hubiese una regresión importante en esta zona pro-púnica, es una reducción demasiado drástica. Millett (1994: 178) recuerda que la exportación de diferentes clases de cerámica romana experimenta grandes variaciones de ritmo según la época, por lo que no puede identificarse ausencia de material con descenso de población. Lo lógico es que buena parte de los asentamientos turdetanos continúe funcionando con relativa normalidad, sin usar objetos diferentes a los que ha conocido durante siglos. De hecho, la cerámica turdetana más tardía por sus formas y decoraciones es relativamente frecuente. 
Así ocurre en la zona oriental de la Bética, según el modelo de evolución entre el final de la etapa turdetana y el comienzo de la romanización propuesto por A. Ruiz para la campiña de Jaén (Ruiz et al. 1991: 32 ss.): desde el s. II a.C. resurgen los oppida, se redistribuye el territorio y se desarrollan sistemas estatales.

La conquista romana no cambia el modelo de asentamiento, aunque Roma lo aprovecha en su beneficio: alianzas con los aristócratas locales, abandono de los centros secundarios, crecimiento económico y expansión hacia las zonas "marginales". Los oppida evolucionan a ciudades muy lentamente, sobre todo desde época cesariana y augustea con el auge de la municipalización. La expansión de las uillae es posterior, del último tercio del s. I d.C. en adelante. Debemos suponer que el paso desde una estructura de poblamiento heredera del horizonte cultural turdetano, a una de colonización rural propia de época augustea fue lento y pausado. La respuesta a una necesidad de recursos agrícolas puesta en marcha tras la conquista romana del territorio va a consistir en la implantación de un sistema o red de uillae, que en parte son de nueva fundación y en parte aprovechan las estructuras existentes.

Con ello la ocupación real durante el período republicano sería bastante más intensa de lo que detecta la prospección. El material propiamente romano entra poco a poco y se hace predominante ya a partir de época de Augusto. En ella se fecha la TSI, presente en 36 uillae y enclaves menores. En conjunto, 44 yacimientos se ocupan con seguridad en los períodos republicano y augústeo.

\section{3. La implantación rural en el Alto Imperio}

A partir de la etapa julio-claudia y en especial desde época flavia, detectamos una auténtica explosión poblacional que coincide con el afianzamiento de los modelos romanos entre la población local. No sólo cambia el modelo de asentamiento, sino también el ajuar doméstico, indiscutiblemente romano y ligado a formas de vida características, voluntariamente aceptadas por la población local según indican diversos autores (Fear 1996, Richardson 1996, v. comentarios de Haley 1997). Los yacimientos se caracterizan por la abundante cerámica de mesa y de cocina, ánforas y dolia, así como materiales de construcción y en algunos casos elementos decorativos, como fragmentos de estuco pintado y parte de una estatuilla de mármol. Los yacimientos con materiales suntuarios son realmente muy pocos: Los Felipes I ( $\left.\mathrm{n}^{\circ} 19\right)$, Santa Iglesia III $\left(n^{\circ} 79\right)$, Repetidor II ( $\left.n^{\circ} 105\right)$, Los Isidros I ( $\left.n^{\circ} 106\right)$, Los Palmares ( $\left.{ }^{\circ} 109\right)$, Puntal de la Jarda $\left(n^{\circ} 122\right)$, Los Mellizos ( $\left.n^{\circ} 130\right)$, El Toril I $\left(n^{\circ} 173\right)$, pero ya se ha indicado que el concepto de uilla que manejamos es en principio indiferente a la suntuosidad de las edificaciones ( $c f r$. no obstante Choclán-Castro 1988: 208, para quienes la simple existencia de vajilla "fina" como las distintas variedades de sigillata ya es indicio suficiente de una pars urbana en el edificio correspondiente).

La vitalidad del poblamiento rural en la primer mitad del siglo I d. C., cuando casi un $87 \%$ de los yacimientos con ocupación romana de Marchena está ya en funcionamiento, parece la apropiada a un ámbito geográfico afectado por los procesos tempranos de colonización y municipalización en la provincia (Sayas 1989). Dentro del marco más amplio del conuentus Astigitanus, una demarcación fiscal y judicial creada por Augusto (Dopico 1986), parece que sólo los territorios correspondientes a colonias o municipios experimentaron este fenómeno romanizador en toda su amplitud. Por el contrario, y en el mismo conuentus, aquellos que dependían de ciudades u oppida estipendiarios, como es el caso del actual término de Palma del Río (Carrillo-Hidalgo 1991) mantuvieron casi intacta hasta bien avanzado el siglo I d.C. la ordenación rural característica de las comunidades turdetanas (Haley 1996; Sáez e.p.).

Las diferencias entre uno y otro caso son consecuencia de las diversas políticas de ordenación territorial aplicadas a comunidades indígenas y romanas (Sáez e.p.). Entre estas últimas, las colonias solían experimentar la parcelación y asignación de tierras a los colonos ad pretium emeritorum. En el caso de municipios como Carmo, la obtención del status privilegiado no supuso necesariamente la parcelación del territorio ni tuvo 
por qué implicar cambios profundos en las estructuras de propiedad de la tierra, aunque la asimilación de las estructuras sociales y económicas a los parámetros metropolitanos daría lugar al surgimiento, al igual que en las colonias, de una estructura territorial "a la romana" que favorecería las exigencias tributarias de Roma (Haley 1997: 497). Ésta se caracterizó por sustituir los viejos esquemas poblacionales turdetanos, basados en los oppida y las turres fortificadas, por otros en que la explotación rural se articuló en circunscripciones denominadas pagi y divididas en fundi (Cfr. CMAPS III: 207: P. Acilius, P. l. Antiochus, sepultus est, fundo suo, pago Singiliense, de Herrera y CIL II 5042-5406: ...fundus Baianus, qui est in agro qui Venerensis uocatur, pago Olbensi..., de Sanlúcar de Barrameda), siendo los pagi circunscripciones fiscales instituidas en la Bética por Augusto (Haley 1997: 496 y n. 5), que a su vez estaban regidas desde establecimientos agrícolas propiedad de particulares con centro en las uillae (Chic 1997: 38).

No obstante, los viejos oppida turdetanos parecen haber perdurado en la zona después de la colonización cesariano-augustea bajo la forma de aglomeraciones rurales, como Vico, Rancho Pozo Blanquillo o PorcúnPorcún Alto, que concentrarían la mayor parte de los incolae no ciudadanos (sobre cuya situación puede verse Rodríguez Neila 1978 y Lomas 1987-1988). Para la zona del Bajo Guadalquivir a comienzos del Imperio, éstos parecen organizarse aún en centuriae o fracciones étnicas (Sáez 1978, Chic 2001) con nombres indígenas, cuyos centros residenciales solían encontrarse en uici o castella. En el territorio que estudiamos, uno de estos núcleos ha mantenido hasta hoy el topónimo de Vico; puede compararse con el caso de los conuicini de Lora del Río (Chic 1993) y con la inscripción CIL II 365: M. Turranius Sulpici[anus], de uico Baedoro, gentis Pinton(um), hallada en Coimbra.

La presencia de contingentes importantes de población indígena libre encuadrada en núcleos rurales dependientes de las ciudades más importantes parece una característica común a muchas ciudades béticas de los primeros años del Imperio, incluidas algunas colonias como Urso (Lex Urs. Cap. 103: incolae contributi). Muchos de los individuos pertenecientes a estas comunidades, desprovistos de los medios económicos que en otro tiempo les aseguraba la propiedad agraria comunitaria, habrían sobrevivido como temporeros en los nuevos dominios agrícolas o se habrían visto abocados a ejercer un "bandolerismo" del que tenemos no pocas noticias para estos momentos (Chic 1997: 39).

La pervivencia de estos núcleos "indígenas" (la desaparición de algunos de los cuales (Porcún Alto) a partir del siglo II d. C. parece indicar que no pudieron adaptarse a un medio social y territorial cada vez más claramente romanizado) en el interior de los territorios coloniales o municipales es, pues, uno de los fenómenos más interesantes desde el punto de vista, no ya sólo jurídico ( $c f r$. Sáez 1998) o social (Chic 1997), sino también territorial, pues introducen un factor de ruptura con las regularidades del modelo colonial de organización y pueden interpretarse como emergencias o discontinuidades topográficas que implican una cierta "estratificación" espacial en los ámbitos geográficos ciudadanos.

La desestructuración social de estas comunidades, que abocaría en los casos extremos a sus miembros al bandidaje, como se ha indicado supra, y en los menos dramáticos a la venta de su fuerza de trabajo por jornal, convertiría en muchos casos en marginales los usos de la tierra asociada a los núcleos indígenas preexistentes (a menudo aún organizados con arreglo a esquemas étnicos que implicaban un concepto comunal de la propiedad de la misma); pero en otras ocasiones, cercanas (Obulcula) o relativamente alejadas (como en el caso de los núcleos del extremo oriental del término astigitano: Isla del Castillo, Carruca, Cerro de las Balas...), estos emplazamientos parecen no sólo haber sobrevivido con éxito a la "romanización", sino haberse sumado decididamente a ella, hasta el punto de alcanzar el estatuto municipal en época flavia. El ejercicio de las magistraturas ciudadanas por parte de los elementos rectores de estas flamantes comunidades los iría sumando al elenco de los ciudadanos romanos de pleno derecho.

Junto a la población indígena, el alto número de establecimientos menores identificados en nuestro trabajo como "granjas" indica la presencia de pequeños posesores, cuya relación con los propietarios fundiarios debió ser variopinta. Muchas de ellas, en especial las de época julio-claudia situadas en el extremo N.E. 
del término y en el Salado, pueden haber sido pequeñas granjas independientes resultado de repartos contemporáneos o posteriores a la colonización del territorio astigitano (contra Durán - Padilla 1990, para quienes es imposible detectar las pequeñas uillae no residenciales de los primeros tiempos de la colonización). Otras muchas deben haber sido dependencias agrícolas o artesanales de las uillae mayores detectadas en las cercanías, tal vez gestionadas por arrendatarios en régimen de locatio-conductio o por institores libres o esclavos, según parece característico de los primeros siglos del Imperio (Foxhall 1990; Sáez 2001; García Vargas 2001) en una provincia donde las estructuras esclavistas no debieron encontrarse ni mucho menos tan desarrolladas como en Italia. Finalmente, algunas sin más documentación que la abundancia de tégulas y fragmentos de TSH y cerámica común, son tal vez necrópolis de establecimientos rurales próximos, cuya diferenciación de los centros menores habitados sólo es posible mediante técnicas de prospección más sofisticadas que las asequibles en una prospección de urgencia sobre un término del tamaño del de Marchena.

Padilla y Durán (1990) han constatado para el término de Écija una clara tendencia a la reducción del número total de establecimientos rurales desde mediados del siglo I d.C., interpretándola como la consecuencia visible de un proceso sostenido de concentración de la propiedad. Este descenso se documenta también en el término de Marchena, aunque su repercusión parece haber sido contrarrestada aquí por otros factores. En números absolutos, sólo puede constatarse la desaparición de 6 establecimientos rurales, entre los que se encuentran uillae de importancia como Cortijo de la Torre II ( $\left.\mathrm{n}^{\circ} 158\right)$. Por el contrario, se documenta ahora la aparición de 9 yacimientos nuevos lo que tal vez deba relacionarse con la intensificación de la explotación económica del territorio favorecida por la política municipal de la dinastía flavia con respecto a Hispania. Una situación similar se detecta en el territorio de Norba Caesarina, donde en la misma época se documenta un poblamiento abundante de distribución uniforme en las zonas más fértiles (Alonso et al. 1994: 81).

Es precisamente en esta segunda mitad del siglo I d.C., y con claridad a partir de época flavia, cuando los territorios "marginales" del conuentus Astigitanus comienzan a dar muestras inequívocas de cambios importantes en las estructuras de explotación agrícola. En una zona tan cercana como la desembocadura del Genil en torno a Palma del Río (Carrillo - Hidalgo 1991), la continuidad de los oppida turdetanos a lo largo del siglo I d.C. es un hecho evidente, existiendo escasos ejemplos de establecimientos agrarios del tipo uilla antes de la época flavia y sólo en las tierras bajas más cercanas a la capital conventual. Más acusado parece este mismo fenómeno en la Subbética cordobesa, donde no se generaliza el sistema de uillae hasta fines del siglo I d.C. (Carrillo 1991).

La municipalización y la romanización más profunda de las estructuras sociales y económicas parecen ir de la mano en este final de siglo, en el que la pervivencia del elemento indígena, al menos en esta zona del Valle, parece ya claramente marginal. Los peregrini que hasta entonces habrían habitado los núcleos rurales de mayor tamaño, dependientes administrativamente de colonias y municipios e integrados en su territorio, habrían visto convertidos sus lugares de origen en flamantes municipios flavios. La concesión del ius Latii por Vespasiano a las provincias hispanas tuvo una vertiente económica en la que apenas se ha reparado (Chic 1994: 30; Id. 1996: 249). Se refiere a la puesta en circulación en beneficio de las ciudades de las rentas de la aristocracia municipal, obligada ahora a invertir en costosas campañas electorales y a gastar su dinero en numerosos actos evergéticos (Melchor 1994). La monetización de las transacciones económicas en el ámbito bético repercutió sin duda en la orientación de los cultivos hacia los emergentes mercados urbanos locales o hacia los centros oficiales de demanda (las fronteras y la capital del Imperio), a los que la annona estatal procuraba abastecimiento en la Provincia (Chic 1988). La época flavia es, gracias a ello, un momento de densa ocupación agrícola en las zonas fértiles del valle del Guadalquivir, como la cuenca del Salado, donde pudo desarrollarse una agricultura especializada orientada al mercado y sostenida por propietarios favorecidos con la nueva situación, pertenecientes tal vez a algunos de los municipios de nueva creación (¿Obulcula?). 
La disminución global del número de granjas a partir del siglo II d.C. es consecuente con el proceso de concentración fundiaria, al que se añade a partir de época antonina el horizonte de un cierto estancamiento económico efectivo a mediados de siglo. Al mismo tiempo, y no necesariamente en conexión con la "crisis" finisecular, ciertas uillae importantes que perduran hasta el Bajo Imperio ven reducirse considerablemente o desaparecer por completo los establecimientos menores situados en sus inmediaciones (entre 100 y $200 \mathrm{~m}$ ), lo que indica tal vez la emergencia y la consolidación de cambios importantes en las estructuras de gestión de los negotia anejos a estos fundi que tenderían a revertir a partir del siglo II avanzado a la gestión directa del propietario del fundus con la consiguiente reducción del número de locatarios independientes (Ligios 1996; Sáez 2001; García Vargas 2001).

\section{4. La implantación rural en épocas medio y bajoimperial y en la Antigüedad Tardía.}

A lo largo de los siglos II y III d.C. se constata una sostenida reducción del numero total de establecimientos mayores (uillae), más acusada en el último siglo y acompañada en muchos casos por un aparente crecimiento en tamaño o al menos en suntuosidad de los establecimientos que sobreviven. Las obras de infraestructura hidráulica detectadas en varios yacimientos pueden permanecer en uso en las últimas épocas de ocupación de los mismos, en relación con el aumento de las necesidades de abastecimiento y distribución de aguas que acompaña al crecimiento en tamaño de los establecimientos rurales y, presumiblemente, del personal ligado a ellos.

Se trata de un fenómeno paralelo a la drástica contracción del número de aglomeraciones rurales, de las que sólo sobrevive hasta el siglo $V$ el Rancho Pozo Blanquillo $\left(n^{\circ} 86\right)$. Esta es una consecuencia probable de las nuevas formas de organización del trabajo en las fincas agrícolas, donde los campesinos independientes a jornal y los granjeros arrendatarios deben haber descendido en beneficio del número de colonos ligados a la explotación rural. Es probable también que estos colonos tuvieran su residencia aparte de unas instalaciones villáticas de grandes dimensiones como las de El Lavadero, casi englobadas hoy en el casco urbano de Marchena, pero lo cierto es que la mayoría no se detectan arqueológicamente, quizás en ausencia de importaciones significativas de sigillatas africanas, lo que parece constituir un problema metodológico característico del trabajo sobre los últimos siglos del Imperio (Haley 1996: 290-1). La excepción la constituirían pequeños emplazamientos como Pasada del Martillo o Loma del Alcaparral II, que surgen precisamente en el siglo IV sin que se hayan detectado en ellas restos de ocupación anterior, y otros como el Cortijo de los Olivos, que siguen en actividad hasta al menos el siglo $\mathrm{V} \mathrm{d}$. C.

Para los años finales del siglo IV y los dos siglos siguientes, de nuevo el enrarecimiento en la distribución de las producciones de mesa africanas hacia el interior de la región puede distorsionar el panorama arqueológico. La descomposición de las estructuras comerciales y la interrupción de las líneas tradicionales de intercambio, al menos por lo que se refiere a las tierras del interior de la Bética, como consecuencia del derrumbe del Imperio Occidental, tuvieron como resultado una reducción sostenida de las importaciones de vajilla de mesa a los establecimientos rurales (Carreté et al. 1995: 280), fenómeno que tal vez esté detrás de esta aparentemente drástica contracción del poblamiento.

Hay una posible explicación, aunque tal vez parcial, a la creciente reducción del número de instalaciones dependientes de unidades rurales mayores en las zonas de campiña más abierta, en un momento en que el colonato parece constituir la forma habitual de explotación agrícola (Sáez-Chic 1983 para el bajo Guadalquivir). Debe buscarse tal vez en la integración funcional en la estructura de la uilla, a partir del siglo II d.C. ya avanzado, de los negotia secundarios propiedad del dominus, que hasta entonces habrían venido gestionando terceros interpuestos (Sáez 2001 y García Vargas 2001, para el caso de Astigi). Pero en general la contracción es tan brutal y la continuidad tan evidente sólo en los emplazamientos de mayor tamaño, que cabe preguntarse si la disminución drástica del número total de uillae detectadas no está reflejando lo que en realidad parece: 
un proceso de concentración de la tierra en pocas manos, culminado en el siglo VI, momento para el que sólo puede señalarse la existencia de Barragua II $\left(n^{\circ}\right.$ 89) y Cerro del Birrete $\left(n^{\circ} 96\right)$, ambas entre el Corbones y la carretera actual Marchena-Carmona. La creación de grandes latifundios cultivados de forma extensiva y orientados a las producciones cerealeras parece apoyada por su ubicación mayoritaria en la vega de Carmona y no en las fértiles terrazas del arroyo Salado, donde en el Alto Imperio debió haber florecido una agricultura especializada con vistas a la exportación y al suministro de los núcleos urbanos más cercanos (supra). Este fenómeno sería consecuencia de la debilidad de la red comercial hacia el exterior y de las formas de gestión de la producción agrícola en el tránsito entre el mundo romano y el visigodo (Padilla 1989: 108-109).

En conclusión, a partir del siglo III d. C. parecen consolidarse importantes cambios en la organización territorial de la zona que determinarán las características que ésta presente a lo largo del Bajo Imperio y la Tardía Antiguiedad. De un territorio ocupado por una red densa de uillae, no todas, hay que recordarlo, arquitectónicamente ricas, de las que dependen centros secundarios ligados a ellas por expedientes diversos o simplemente independientes y junto a las que perviven núcleos indígenas, se pasa a otro en que el número y la densidad de estos establecimientos villáticos decrece considerablemente, al tiempo que, hemos de suponer, aunque no hay constancia empírica directa, excepto tal vez el caso de El Lavadero, aumentan en tamaño y suntuosidad e incluyen en su seno los establecimientos artesanales menores. La suerte de las aglomeraciones rurales en la región es variada. Aunque no existe constancia de que las incluidas en el término de Marchena alcanzasen el estatuto municipal (debe descartarse la identificación de Artigi con el Cortijo de la Torre), otras cercanas como Obulcula parecen haber pervivido durante algún tiempo como núcleos urbanos relativamente independientes.

\section{CONCLUSIONES}

Las conclusiones extraídas de una prospección superficial restringida a un marco administrativo actual no tienen más remedio que ser parciales y provisionales: por las limitaciones de un territorio así seleccionado y por las propias de la documentación superficial de los yacimientos. Éstas pasan por remociones del terreno, arrastres debidos a la erosión o a la acción humana, e incluso el hecho de poner de manifiesto sólo las fases más recientes de un lugar, pudiendo quedar ocultos estratos más antiguos (en el mismo sentido Arasa 2001: 17).

A pesar de estas dificultades de interpretación del registro, puede concluirse con ciertas garantías que las modificaciones en la zona en consideración a lo largo del período romano han consistido en una continua estructuración y desestructuración territorial en virtud de la cual los viejos núcleos de habitación turdetanos han cedido su lugar, conviviendo algún tiempo con ella como elementos marginales, a una red importante de establecimientos rurales (uillae) cuya aparición debe relacionarse con las primitivas formas de implantación romana. La homogeneización "paisajística" del ámbito territorial considerado a partir de época flavia parece haber consistido en la relativamente rápida descomposición de esta red de establecimientos rurales con sus dependencias propias en beneficio de una serie limitada de uillae que procede de los primeros tiempos de la colonización y la municipalización y cuya vida alcanza los años finales del Imperio Romano de Occidente. Su presencia y perduración parecen reflejar la concentración de la gestión - si no de la propiedadagrícola y de la organización efectiva del territorio de las ciudades en unas cuantas manos. Los problemas relacionados con la distribución comercial y con la visibilidad arqueológica de ciertas formas de vajilla de importación tardía no permiten por ahora descender en el análisis hasta los establecimientos menores que puedan documentar la extensión de colonato en la región. La desaparición de los estratos superiores del yacimiento de Vico nos priva igualmente de una documentación valiosa para determinar el papel desempeñado en estos momentos por las aglomeraciones urbanas, pero la pervivencia del topónimo hasta nuestros días tal vez indique una larga perduración cronológica y funcional a través del tiempo. 


\section{BIBLIOGRAFÍA}

ALONSO, Ma A.; CERRILLO, E. y FERNÁNDEZ, J. Ma . (1992-1993): "Tres ejemplos de poblamiento rural romano en torno a ciudades de la Vía de la Plata: Augusta Emerita, Norba Caesarina y Capara", Studia Historica. Historia Antigua 10-11: 67-87.

ARBOIS DE JUBAINVILLE, H. d'. (1886): "Le fundus et la ville en Gaule", CRAI: 306-11.

ARASA, F. (2001): La romanització a les comarques septentrionales del litoral valencià. Valencia.

BINTLIFF, J. (1985): “The Boeotia survey”, en Th. MACREDY y F. H. THOMPSON (eds.), Archaeological Field Survey in Britain and Abroad: 196-216. Londres.

CAMBI, F. y TERRENATO, N. (1994): Introduzione all'archeologia dei paesaggi. Roma.

CARANDINI, A. (1980): "Il vigneto e la vigna nel fondo di Settefinestre nel Cosano: un caso di produzione agricola per il mercato trasmarino", MAAR XXXVI: 1-10.

(1989): "La villa romana e la piantagione schiavistica", Storia di Roma 4: 101-200. Turín.

CARO, R. (1634 / 1998 ed. facsímil): Antigüedades y Principado de la Ilustríssima Ciudad de Sevilla y Chorographia de su Convento Iurídico o Antigua Chancillería. Sevilla.

CARRETÉ, J. M.; KEAY, S. y MILLET, M. (1995): A Roman provincial capital and its hinterland. The survey of the territory of Tarragona, Spain, 1985-1990. Ann Arbor (MI).

CARRILLO, J. R. (1991): "El poblamiento romano en la Subbética cordobesa", Anales de Arqueología Cordobesa 2: 225-252.

CARRILLO, J. R. y HIDALGO, R. (1991): “Aproximación al estudio del poblamiento romano en la comarca de Palma del Río (Córdoba): la implantación territorial", Ariadna 8: 37-68.

CHIC, G. (1988): Epigrafía anfórica de la Bética II. Consideraciones sobre la annona. Écija.

— (1993): "Convecinos en las tierras de Lora del Río. Reflexiones en torno a una nueva inscripción axatitana de época romana", Revista de Estudios Locales de Lora del Río 4: 7-13.

(1994): La proyección económica de la Bética en el Imperio Romano (época altoimperial). Sevilla. (1997): Historia económica de la Bética en la época de Augusto. Sevilla.

CHOCLÁN, C. y CASTRO, M. (1988): "La campiña del Alto Guadalquivir en los siglos I-II d.C. Asentamientos, estructura agraria y mercado", Arqueología Espacial 12: 205-221.

COLLANTES DE TERÁN, F. (s.a.): Fichas relativas a Marchena con destino a un volumen no publicado del Catálogo Monumental y Artístico de la Provincia de Sevilla (= "Papeles de Collantes").

DOPICO, D. (1986): "Los conuentus iuridici. Origen, cronología y naturaleza histórica", Gerión 4: 265-283. DURÁN, V. y PADILLA, A. (1990): El poblamiento antiguo en el término municipal de Écija. Écija.

Estudio agrobiológico... (1962): CENTRO DE EDAFOLOGÍA Y BIOLOGÍA APLICADA DEL CUARTO (C.S.I.C.): Estudio agrobiológico de la provincia de Sevilla. Sevilla.

FEARS, A. T. (1996): Rome and Baetica. Urbanization in Southern Spain c. 50 BC - AD 150. Oxford.

FERNÁNDEZ-POSSE, Ma D. y ÁLVARO, E. de (1993): "Bases para un inventario de yacimientos arqueológicos", en JIMENO, A. et alii (eds.): Inventarios y cartas arqueológicas. Homenaje a Blas Taracena (Soria, 1991): 65-72. Valladolid.

FERRER, E.; ORIA, M. y GARCÍA, E. (2000): "La prospección arqueológica superficial del Término Municipal de Marchena y la conservación del Patrimonio Histórico", V Jornadas de Historia de Marchena (Marchena, 1999): 75-103. Sevilla.

FOLEY, R. (1981): "Off-site archaeology, an alternative approach for the short-site", en HODDER, I. et alii: Pattern of the Past: 157-87. Cambridge.

FOXHALL, L. (1990): "The Dependent Tenant: Land Leasing and Labour in Italy and Greece" JRS LXXX: 97-114. 
GARCÍA VARGAS, E. (2001): "La producción de ánforas "romanas" en el sur de Hispania: República y. Alto Imperio", Congreso Internacional Ex Baetica Amphorae. Conservas, aceite y vino de la Bética en el Imperio Romano. (Sevilla-Écija, diciembre de 1998) I: 57-74. Écija.

GONZÁLEZ, J. (1989): “El repartimiento de Écija”, Actas del I Congreso de Historia de Écija: 337-365. Écija.

— (1996): Corpus de Inscripciones Latinas de Andalucía. II: Sevilla, tomo III: La campiña. Sevilla (= CILA III.3).

(1999): "Nuevos fragmentos de la Lex Flavia Municipalis pertenecientes a la Lex Villonensis y a otros municipios de nombre desconocido", en GONZÁLEZ, J. (ed.): Ciudades privilegiadas en el Occidente romano: $239-245$. Sevilla.

GORGES, J. G. (1979): Les villes hispano-romaines. París.

HALEY, E. (1996): "Rural settlement in the Conventus Astigitanus (Baetica) under the Flavians", Phoenix L, 3-4: 283-303.

(1997): "Town and country: the acculturation of S. Spain", JRA 10: 495-503.

HERNÁNDEZ DÍAZ, J.; SANCHO CORBACHO, A. y COLLANTES DE TERÁN, F. (1951): Catálogo monumental y artístico de la provincia de Sevilla. T. III: Dos Hermanas-Écija (CMAPS III).

HODDER, I. y ORTON, C. (1990 [1976]): Análisis espacial en Arqueología, Barcelona.

JACQUES, (1990): "Une exemple de concentracion foncière en Bétique d'aprés la temoignage des timbres amphoriques d'une famille clarissime", MEFRA 102: 865-899.

LIGIOS, M. A. (1996): Interpretazione giuridica e realtà economica dell' istrumentum fundi tra il I sec. a. C. ed il III sec. $d$ C. Nápoles.

LOMAS, J. (1987-1988): "De la condición social de los incolae con especial referencia a Hispania", Habis 18-19: 387-397.

MELCHOR, E. (1994): El mecenazgo cívico en la Bética. Córdoba.

MILLETT, M. (1994): "Roman towns and their territories: an archaeological perspective", en RICH, J. y WALLACE-HADRILL, A. (eds.): City and country in the Ancient World: 169-189. Londres.

OLMOS, R. (1993): “El origen de las cartas arqueológicas y el Mapa del Mundo Romano”, en JIMENO, A. et alii (eds): Inventarios y cartas arqueológicas. Homenaje a Blas Taracena (Soria, 1991): 45-56. Valladolid.

ORDÓÑEZ, S. (1996): “La romanización en Marchena”, en Actas de las I Jornadas de Historia de Marchena (Marchena, 1995): 37-72. Sevilla.

OREJAS, A. (1991): "Arqueología del paisaje: historia, problemas y perspectivas", AEspA 64: 191-230.

- (1995): Del marco geográfico a la arqueología del paisaje. Madrid.

- (1998): “El estudio del paisaje: visiones desde la Arqueología", Arqueología del Paisaje, Arqueología Espacial 19-20: 9-19.

ORIA, M. (2001): "Infraestructuras hidráulicas en la vega del río Corbones (Marchena, Sevilla)", I Congreso Internacional de Historia Antigua "La Península Ibérica hace 2000 años" (Valladolid, 2000): 669-674. Valladolid.

PADILLA, A. (1989): La provincia romana de la Bética (253-422). Écija.

PÉREZ LOSADA, F. (1987): "Sobre o concepto de villa no mundo romano", Cuadernos de Arqueología 4: 79-110.

PONSICH, M. (1974): Implantation rurale antique sur le bas-Guadalquivir I. Madrid.

- (1979): Implantation rurale antique sur le bas-Guadalquivir II. Madrid. (1984): Implantation rurale antique sur le bas-Guadalquivir III. Madrid. (1991): Implantation rurale antique sur le bas-Guadalquivir IV. Madrid.

POTTER, T. W. (1982): "Prospection en surface: théorie et practique", en FEVRIER, P. A. y LEVEAU, P. (eds.): Villes et campagnes dans l'Empire Romain (Aix-en-Provence, 1980): 19-41. Aix-en-Provence. 
PRIETO, A. (1980): "La pervivencia del elemento indígena en la Bética", Faventia 2/1: 37-46.

RICHARDSON, J. S. (1996): The Romans in Spain. Oxford.

RODRÍGUEZ NEILA, J.F. (1978): "La situación socio-política de los incolae en el mundo romano, MHA 2: 147-169.

ROMERO, C. (1987): "Un horno de cerámica común romana en Marchena (Sevilla)", AAA'85-III: 285-287.

RUIZ, A.; MOLINOS, M. y CASTRO, M. (1991): "Settlement and continuity in the territory of the Guadalquivir Valley $\left(6^{\text {th }}\right.$ century BC - ${ }^{\text {st }}$ century AD)", en BARKER, G. W. y LLOYD, J. A. (eds.): Roman landscapes. Archaeological survey in the Mediterranean region: 29-36. Londres.

RUIZ DEL ÁRBOL, M. (2001): Organización y explotación del territorio en el Noreste de Lusitania en época altoimperial. Madrid. Tesis Doctoral Inédita.

RUIZ, M. Ma . (1985): Carta Arqueológica de la Campiña sevillana, zona S.E. I. Sevilla.

RUIZ-ZAPATERO, G. y FERNÁNDEZ, V. M. (1993): "Prospección de superficie, técnicas de muestreo y recogida de información", en JIMENO, A. et alii (eds): Inventarios y cartas arqueológicas. Homenaje a Blas Taracena (Soria, 1991): 87-96. Valladolid.

SÁEZ, P. (1978): "Las centurias de la Bética", Habis 9: 257-271.

- (1998): "Transformaciones agrarias de la República al Imperio en la zona meridional de España", en MANGAS, J. (ed.): Italia e Hispania en la crisis de la República romana. Actas del III Congreso Hispano-Italiano (Toledo 20-24 de septiembre de 1993): 99-106. Madrid.

(1999): "Comunidades indígenas en el Sur de la Península Ibérica: Dos notas", en VILLAR, F.; BELTRÁN, F. (eds.): Pueblos, lenguas y escrituras en la España prerromana (Salamanca, 1999): 175-181. Salamanca.

(2001): "Los envases anfóricos como instrumentum fundi", Congreso Internacional Ex Baetica Amphorae. Conservas, aceite y vino de la Bética en el Imperio Romano. (Sevilla-Écija, diciembre de 1998) IV: 1171-1181. Écija.

- (e. p.): "Algunas consideraciones sobre el territorio de las ciudades de la Bética", en GONZÁLEZ ROMÁN, C. (ed.): La Bética en su problemática Histórica 3, Granada.

SÁEZ, P. y CHIC, G. (1983): "La epigrafía de las ánforas olearias béticas como posible fuente para el estudio del colonato en la Bética", II Congreso Internacional sobre Producción y Comercio del Aceite en la Antigüedad: 193-210. Madrid.

SÁEZ, P. y ORDÓÑEZ, S. (e.p.): “La delimitación territorial”, en SÁEZ, P. et alii: Procesos diacrónicos de teritorialización: el modelo de Écija. Écija.

SÁEZ, P.; ORDÓÑEZ, S.; GARCÍA, E. y GARCÍA-DILS, S. (e.p.): Carta Arqueológica Rural y Urbana de Écija. Écija.

SANZ, M. J. (1976): "El Repartimiento de Écija”, Historia. Instituciones. Documentos 3: 533-551.

SAYAS, J. J. (1989): “Colonización y municipalización bajo César y Augusto: Hispania Ulterior", en Aspectos de la colonización y municipalización de Hispania: 33-69. Mérida.

SNODGRASS, A. (1990 [1987]): Arqueología de Grecia. Barcelona.

STYLOW, A. U. (1999): "Entre edictum y lex. A propósito de una nueva ley municipal flavia del término de Écija", en GONZÁLEZ, J. (ed.): Ciudades privilegiadas en el Occidente romano: 229-237. Sevilla.

TRAINA, G. (1990): Ambienti e paesaggi di Roma antica. Roma.

VALENCIA, R. (1998): "La cora de Carmona (712-1247): medio físico y humano", Actas del I Congreso de historia de Carmona. Edad Media. Congreso conmemorativo del 750 aniversario de la conquista de la ciudad de Carmona por Fernando III. 1247. Sevilla.

VALENCIA, R. (1988): "Los territorios de la cora de Écija en época árabe", Actas del I Congreso sobre historia de Écija I: 315-335. Écija. 


\section{CONTINUIDAD DE LOS YACIMIENTOS ROMANOS EN EL TÉRMINO DE MARCHENA}

(Sombreado oscuro: ocupación documentada por cerámicas de fecha segura; sombreado claro: ocupación probable pero documentada por cerámicas de fecha amplia poco precisa.)

\begin{tabular}{|c|c|c|c|c|c|c|c|c|c|}
\hline \multirow{2}{*}{$\begin{array}{c}\text { Períodos } \\
\text { Yacimientos }\end{array}$} & \multicolumn{2}{|c|}{ REPÚBLICA } & \multicolumn{4}{|c|}{ ALTO IMPERIO } & \multirow{2}{*}{$\begin{array}{l}\text { s. III } \\
\text { s. III } \\
\text { d. C. }\end{array}$} & \multicolumn{2}{|c|}{ BAJO IMPERIO } \\
\hline & $\begin{array}{l}\text { s. II } \\
\text { a. C. }\end{array}$ & $\begin{array}{l}\text { s. I } \\
\text { a.C. }\end{array}$ & $\begin{array}{c}1^{a} 1 / 2 \\
\text { s. I d.C. }\end{array}$ & $\begin{array}{c}2^{a}{ }^{1 / 2} \\
\text { s. I d.C. }\end{array}$ & $\begin{array}{c}1^{a} 1 / 2 \\
\text { s. II d.C. }\end{array}$ & $\begin{array}{c}2^{a} 1 / 2 \\
\text { s. II d.C. }\end{array}$ & & $\begin{array}{l}\text { s. IV } \\
\text { d. C. }\end{array}$ & $\begin{array}{l}\text { s. V } \\
\text { d. C. }\end{array}$ \\
\hline \multicolumn{10}{|c|}{ 1. Ranchos del Porcún } \\
\hline \multicolumn{10}{|c|}{ 3. Ladera del Tarazanil } \\
\hline \multicolumn{10}{|l|}{ 6. Grullo Grande I } \\
\hline \multicolumn{10}{|l|}{ 7. Grullo Grande II } \\
\hline \multicolumn{10}{|l|}{ 10. P. del Martillo I } \\
\hline \multicolumn{10}{|l|}{ 11. P. del Martillo II } \\
\hline \multicolumn{10}{|l|}{ 12. Tarajal } \\
\hline \multicolumn{10}{|c|}{ 13. Laderas Montalbán } \\
\hline \multicolumn{10}{|l|}{ 17. Sta. Ana I } \\
\hline \multicolumn{10}{|l|}{ 19. Los Felipes I } \\
\hline \multicolumn{10}{|l|}{ 20. Los Felipes II } \\
\hline \multicolumn{10}{|l|}{ 21. Los Felipes III } \\
\hline \multicolumn{10}{|l|}{ 23. Los Galindos I } \\
\hline \multicolumn{10}{|l|}{ 24. Los Galindos II } \\
\hline \multicolumn{10}{|l|}{ 25. Rancho Luna } \\
\hline \multicolumn{10}{|l|}{ 26. Los Vicentes I } \\
\hline \multicolumn{10}{|l|}{ 30. La Charca II } \\
\hline \multicolumn{10}{|c|}{ 32. Loma del Mostazar II } \\
\hline \multicolumn{10}{|l|}{ 33. Los Camorros I } \\
\hline \multicolumn{10}{|l|}{ 35. Clarebout I } \\
\hline \multicolumn{10}{|l|}{ 36. Clarebout II } \\
\hline \multicolumn{10}{|l|}{ 40. Salado II } \\
\hline \multicolumn{10}{|l|}{ 41. Salado IIb } \\
\hline \multicolumn{10}{|l|}{ 46. Verdeja III } \\
\hline 47. Donadío I & & & & & & & & & \\
\hline 48. Cerro Motilla & & & & & & & & & \\
\hline 49. La Lombriz Ib & & & & & & & & & \\
\hline 50. La Lombriz II & & & & & & & & & \\
\hline 51. La Lombriz III & & & & & & & & & \\
\hline
\end{tabular}




\begin{tabular}{|c|c|c|c|c|c|c|c|c|c|}
\hline \multirow{2}{*}{$\begin{array}{c}\text { Períodos } \\
\text { Yacimientos }\end{array}$} & \multicolumn{2}{|c|}{ REPÚBLICA } & \multicolumn{4}{|c|}{ ALTO IMPERIO } & \multirow{2}{*}{$\begin{array}{l}\text { S. III } \\
\text { s. III } \\
\text { d. C. }\end{array}$} & \multicolumn{2}{|c|}{ BAJO IMPERIO } \\
\hline & $\begin{array}{l}\text { s. II } \\
\text { a. C. }\end{array}$ & $\begin{array}{l}\text { s. I } \\
\text { a.C. }\end{array}$ & $\begin{array}{c}1^{\mathrm{a}} 1 / 2 \\
\text { s. I d.C. }\end{array}$ & $\begin{array}{c}2^{a} 1 / 2 \\
\text { s. I d.C. }\end{array}$ & $\begin{array}{c}1^{\mathrm{a}} \mathrm{l} / 2 \\
\text { s. II d.C. }\end{array}$ & $\begin{array}{c}2^{\mathrm{a}} \mathrm{l} / \mathrm{2} \\
\text { s. II d.C. }\end{array}$ & & $\begin{array}{l}\text { s. IV } \\
\text { d. C. }\end{array}$ & $\begin{array}{l}\text { s. V } \\
\text { d. C. }\end{array}$ \\
\hline \multicolumn{10}{|l|}{ 52. La Junquera } \\
\hline \multicolumn{10}{|l|}{ 53. Cerro Gordo } \\
\hline \multicolumn{10}{|l|}{ 54. La Platosa I } \\
\hline \multicolumn{10}{|l|}{ 56. La Platosa III } \\
\hline \multicolumn{10}{|l|}{ 61. Loma Alcaparral I } \\
\hline \multicolumn{10}{|l|}{ 62. Loma Alcaparral II } \\
\hline \multicolumn{10}{|l|}{ 63. Cerros de S. Ignacio } \\
\hline \multicolumn{10}{|l|}{ 65. Porcún Alto I } \\
\hline \multicolumn{10}{|l|}{ 66. Porcún Alto II } \\
\hline \multicolumn{10}{|l|}{ 67. Porcún Alto III } \\
\hline \multicolumn{10}{|l|}{ 68. Porcún I } \\
\hline \multicolumn{10}{|l|}{ 69. Porcún II } \\
\hline \multicolumn{10}{|l|}{ 75. Pozo del Carretero } \\
\hline \multicolumn{10}{|l|}{ 76. Arroyo Carretero } \\
\hline \multicolumn{10}{|l|}{ 77. Sta. Iglesia I } \\
\hline \multicolumn{10}{|l|}{ 78. Sta. Iglesia II } \\
\hline \multicolumn{10}{|l|}{ 79. Sta. Iglesia III } \\
\hline \multicolumn{10}{|l|}{ 82. La Zorrilla I } \\
\hline \multicolumn{10}{|l|}{ 83. La Zorrilla II } \\
\hline \multicolumn{10}{|l|}{ 85. La Torre II } \\
\hline \multicolumn{10}{|l|}{ 86. R. Pozo Blanquillo } \\
\hline 87. La Torviscosa & & & & & & & & & \\
\hline 89. Barragua II & & & & & & & & & \\
\hline 92. Cortijo de los Olivo & & & & & & & & & \\
\hline 95. Cortijo José Antoni & & & & & & & & & \\
\hline 96. Cerro del Birrete & & & & & & & & & \\
\hline 97. La Gamorra I & & & & & & & & & \\
\hline 100. Los Medianos I & & & & & & & & & \\
\hline 102. Los Medianos III & & & & & & & & & \\
\hline 104. Repetidor I & & & & & & & & & \\
\hline 105. Repetidor II & & & & & & & & & \\
\hline 106. Los Isidros I & & & & & & & & & \\
\hline 107. Los Isidros II & & & & & & & & & \\
\hline 108. Los Isidros III & & & & & & & & & \\
\hline
\end{tabular}




\begin{tabular}{|c|c|c|c|c|c|c|c|c|c|}
\hline \multirow{2}{*}{$\begin{array}{c}\text { Períodos } \\
\text { Yacimientos }\end{array}$} & \multicolumn{2}{|c|}{ REPÚBLICA } & \multicolumn{4}{|c|}{ ALTO IMPERIO } & \multirow{2}{*}{$\begin{array}{l}\text { s. III } \\
\text { s. III } \\
\text { d. C. }\end{array}$} & \multicolumn{2}{|c|}{ BAJO IMPERIO } \\
\hline & $\begin{array}{l}\text { s. II } \\
\text { a. C. }\end{array}$ & $\begin{array}{l}\text { s. I } \\
\text { a.C. }\end{array}$ & $\begin{array}{l}1^{a} 1 / 2 \\
\text { s. I d.C. }\end{array}$ & $\begin{array}{l}2^{\mathrm{a}} 1 / 2 \\
\text { s. I d.C. }\end{array}$ & $\begin{array}{l}1^{a} 1 / 2 \\
\text { s. II d.C. }\end{array}$ & $\begin{array}{l}2^{a} 1 / 2 \\
\text { s. II d.C. }\end{array}$ & & $\begin{array}{l}\text { s. IV } \\
\text { d. C. }\end{array}$ & $\begin{array}{l}\text { s. V } \\
\text { d. C. }\end{array}$ \\
\hline \multicolumn{10}{|l|}{ 109. Los Palmares } \\
\hline \multicolumn{10}{|l|}{ 112. Carrascal II } \\
\hline \multicolumn{10}{|l|}{ 113. Carrascal III } \\
\hline \multicolumn{10}{|l|}{ 114. Carrascal IV } \\
\hline \multicolumn{10}{|c|}{ 115. Casilla Pozo Salado } \\
\hline \multicolumn{10}{|l|}{ 116. La Batalá } \\
\hline \multicolumn{10}{|c|}{$\begin{array}{l}\text { 119. Rancho I } \\
\text { (Cortijo del Ahorcado) }\end{array}$} \\
\hline \multicolumn{10}{|l|}{ 120. Rancho II } \\
\hline \multicolumn{10}{|l|}{ 122. Puntal de la Jarda } \\
\hline \multicolumn{10}{|l|}{ 123. A. Pedro López I } \\
\hline \multicolumn{10}{|l|}{ 125. A. Pedro López III } \\
\hline \multicolumn{10}{|l|}{ 128. Lomas Maravilloso } \\
\hline \multicolumn{10}{|l|}{ 130. Los Mellizos } \\
\hline \multicolumn{10}{|c|}{ 131. C. del Maravilloso I } \\
\hline \multicolumn{10}{|l|}{ 133. C. Maravilloso III } \\
\hline \multicolumn{10}{|l|}{ 134. C. Maravilloso IV } \\
\hline \multicolumn{10}{|l|}{ 137. El Lavadero } \\
\hline \multicolumn{10}{|l|}{ 141. Huerta Arjona } \\
\hline \multicolumn{10}{|l|}{ 142. Vistalegre I } \\
\hline \multicolumn{10}{|l|}{ 145. Cerro del Orégano } \\
\hline \multicolumn{10}{|l|}{ 148. Angostillo } \\
\hline 150. A. Hondo Rambla & & & & & & & & & \\
\hline 153. Vico & & & & & & & & & \\
\hline 155. Rancho Melero & & & & & & & & & \\
\hline 156. Los Cortés & & & & & & & & & \\
\hline 158. Cortijo de la Torre & & & & & & & & & \\
\hline 159. C. de la Torre II & & & & & & & & & \\
\hline 160. C. de la Torre III & & & & & & & & & \\
\hline 162. Ojuelos & & & & & & & & & \\
\hline 163. Pagodulce I & & & & & & & & & \\
\hline 165. Pagodulce III & & & & & & & & & \\
\hline 167. Cortijo del Río I & & & & & & & & & \\
\hline 168. Cortijo del Río II & & & & & & & & & \\
\hline 173. El Toril I & & & & & & & & & \\
\hline
\end{tabular}




\begin{tabular}{|c|c|c|c|c|c|c|c|c|c|}
\hline \multirow{2}{*}{$\begin{array}{c}\text { Períodos } \\
\text { Yacimientos }\end{array}$} & \multicolumn{2}{|c|}{ REPÚBLICA } & \multicolumn{4}{|c|}{ ALTO IMPERIO } & \multirow{2}{*}{$\begin{array}{l}\text { s. III } \\
\text { s. III } \\
\text { d. C. }\end{array}$} & \multicolumn{2}{|c|}{ BAJO IMPERIO } \\
\hline & $\begin{array}{l}\text { s. II } \\
\text { a. C. }\end{array}$ & $\begin{array}{l}\text { s. I } \\
\text { a.C. }\end{array}$ & $\begin{array}{c}1^{a} 1 / 2 \\
\text { s. I d.C. }\end{array}$ & $\begin{array}{c}2^{\mathrm{a}} 1 / 2 \\
\text { s. I d.C. }\end{array}$ & $\begin{array}{c}1^{\mathrm{a}} 1 / 2 \\
\text { s. II d.C. }\end{array}$ & $\begin{array}{c}2^{\mathrm{a}} 1 / 2 \\
\text { s. II d.C. }\end{array}$ & & $\begin{array}{l}\text { s. IV } \\
\text { d. C. }\end{array}$ & $\begin{array}{l}\text { s. V } \\
\text { d. C. }\end{array}$ \\
\hline \multicolumn{10}{|l|}{ 174. El Toril II } \\
\hline \multicolumn{10}{|l|}{ 176. Rancho Cazolita } \\
\hline \multicolumn{10}{|l|}{ 178. R. Fernandita II } \\
\hline \multicolumn{10}{|l|}{ 179. Cagancha } \\
\hline \multicolumn{10}{|l|}{ 180. El Cañuelo I } \\
\hline \multicolumn{10}{|l|}{ 183. La Lombriz I } \\
\hline \multicolumn{10}{|l|}{ 187. Vistalegre II } \\
\hline \multicolumn{10}{|l|}{ 188. Cortijo de Vico } \\
\hline \multicolumn{10}{|l|}{ 190. Verdeja IV } \\
\hline \multicolumn{10}{|c|}{ 200. Haza de las Monjas } \\
\hline \multicolumn{10}{|l|}{ 203. La Gamorra II } \\
\hline \multicolumn{10}{|c|}{ 204. C. de los Palmeños } \\
\hline \multicolumn{10}{|l|}{ 205. Cerro del Judío } \\
\hline \multicolumn{10}{|l|}{ FT2. Transformador } \\
\hline \multicolumn{10}{|l|}{ FT4. R. Fernandita I } \\
\hline FT5. Donadío II & & & & & & & & & \\
\hline
\end{tabular}




\section{Yacimientos Romanos del Termino de Marchena}

\section{Epoca Republicana}

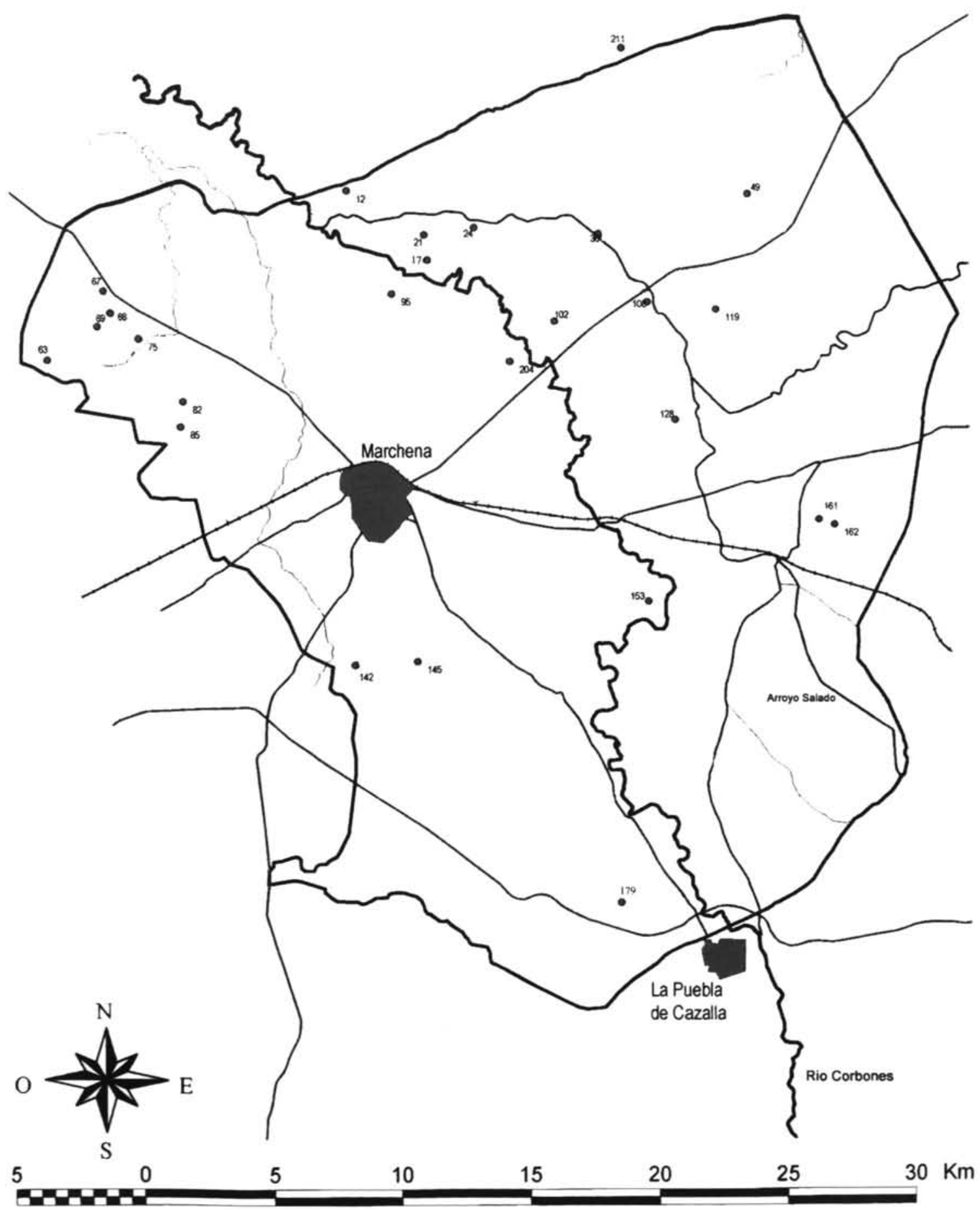




\section{Yacimientos Romanos del Termino de Marchena}

\section{Epoca Altolmperial}

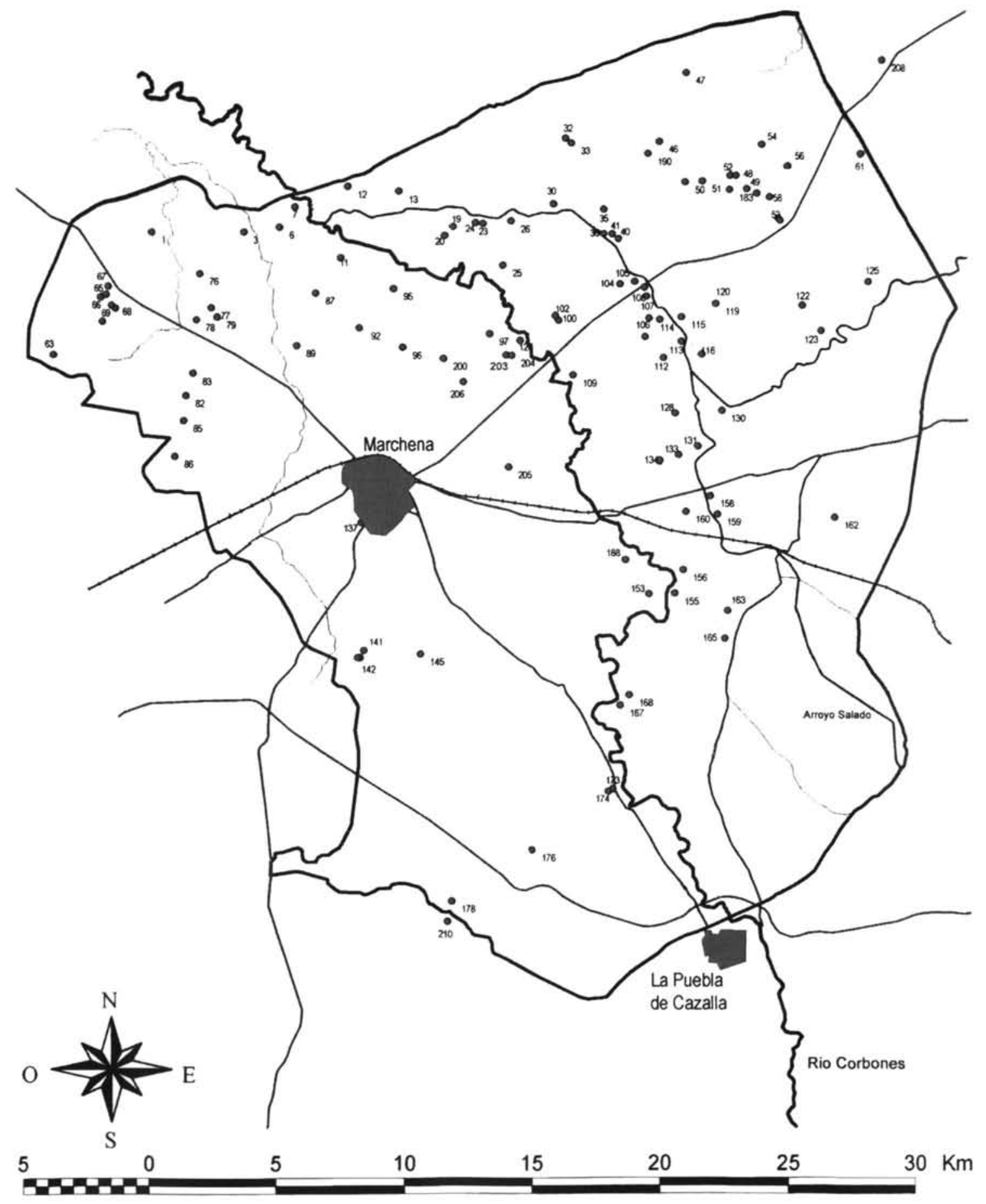




\section{Yacimientos Romanos del Termino de Marchena}

\section{Epoca Bajolmperial}

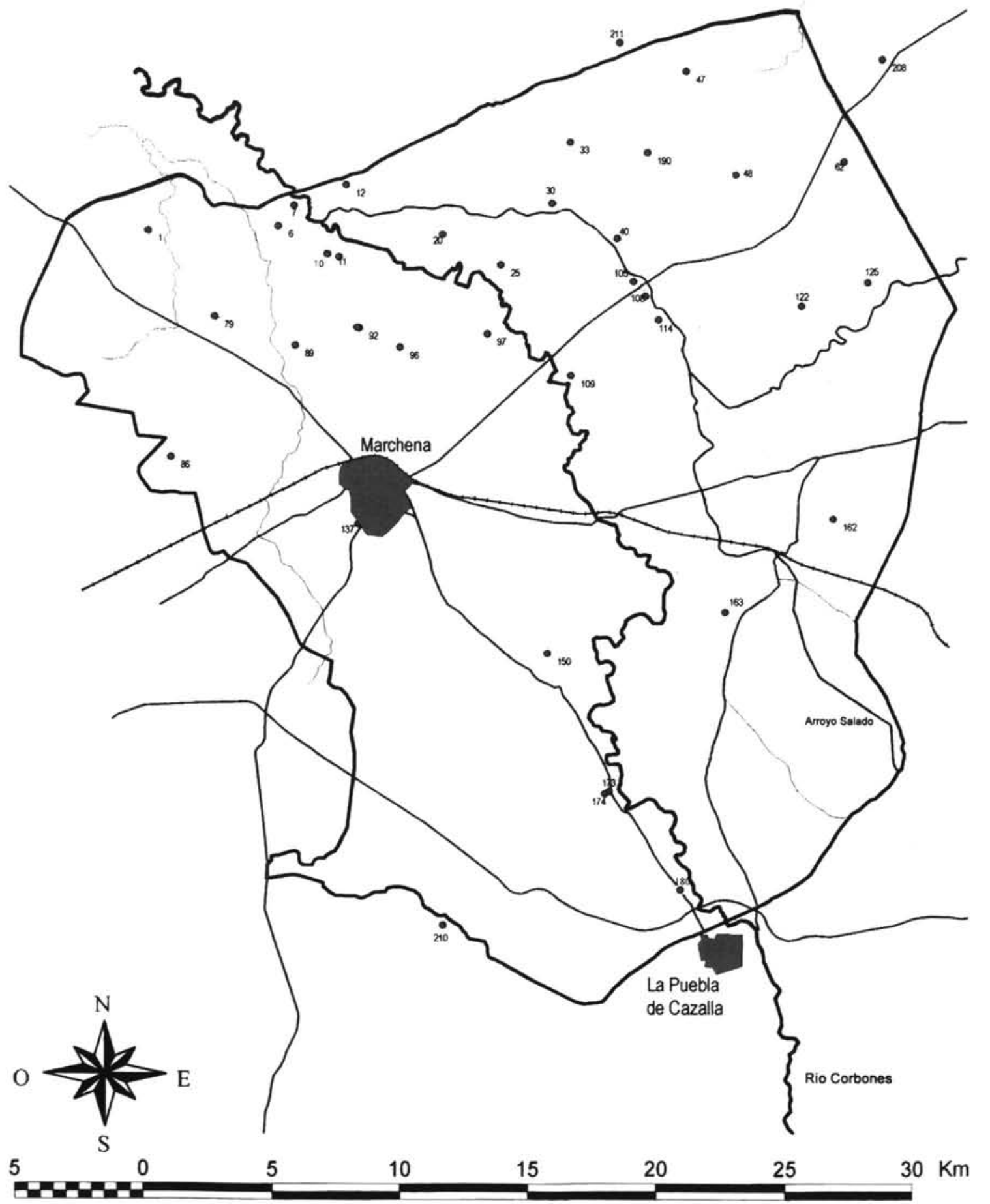

